\title{
Observations of nonmethane organic compounds during ARCTAS - Part 1: Biomass burning emissions and plume enhancements
}

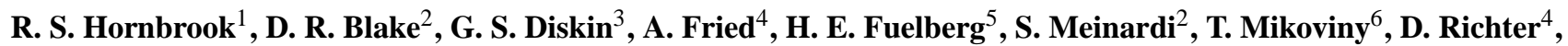 \\ G. W. Sachse ${ }^{3}$, S. A. Vay ${ }^{3}$, J. Walega ${ }^{4}$, P. Weibring ${ }^{4}$, A. J. Weinheimer ${ }^{1}$, C. Wiedinmyer ${ }^{1}$, A. Wisthaler ${ }^{6}$, A. Hills ${ }^{1}$, \\ D. D. Riemer ${ }^{7}$, and E. C. Apel ${ }^{1}$ \\ ${ }^{1}$ Atmospheric Chemistry Division, National Center for Atmospheric Research, Boulder, Colorado, USA \\ ${ }^{2}$ Department of Chemistry, University of California Irvine, Irvine, California, USA \\ ${ }^{3}$ NASA Langley Research Center, Hampton, Virginia, USA \\ ${ }^{4}$ Earth Observing Laboratory, National Center for Atmospheric Research, Boulder, Colorado, USA \\ ${ }^{5}$ Department of Meteorology, Florida State University, Tallahassee, Florida, USA \\ ${ }^{6}$ Institut für Ionenphysik \& Angewandte Physik, University of Innsbruck, Innsbruck, Austria \\ ${ }^{7}$ Rosenstiel School of Marine and Atmospheric Science, University of Miami, Miami, Florida, USA
}

Received: 1 April 2011 - Published in Atmos. Chem. Phys. Discuss.: 9 May 2011

Revised: 21 October 2011 - Accepted: 26 October 2011 - Published: 9 November 2011

\begin{abstract}
Mixing ratios of a large number of nonmethane organic compounds (NMOCs) were observed by the Trace Organic Gas Analyzer (TOGA) on board the NASA DC-8 as part of the Arctic Research of the Composition of the Troposphere from Aircraft and Satellites (ARCTAS) field campaign. Many of these NMOCs were observed concurrently by one or both of two other NMOC measurement techniques on board the DC-8: proton-transfer-reaction mass spectrometry (PTR-MS) and whole air canister sampling (WAS). A comparison of these measurements to the data from TOGA indicates good agreement for the majority of co-measured NMOCs. The ARCTAS study, which included both spring and summer deployments, provided opportunities to sample a large number of biomass burning (BB) plumes with origins in Asia, California and central Canada, ranging from very recent emissions to plumes aged one week or more. For this analysis, BB smoke interceptions were grouped by flight, source region and, in some cases, time of day, generating 40 identified BB plumes for analysis. Normalized excess mixing ratios (NEMRs) to $\mathrm{CO}$ were determined for each of the 40 plumes for up to 19 different NMOCs or NMOC groups. Although the majority of observed NEMRs for individual NMOCs or NMOC groups were in agreement with previously-reported values, the observed NEMRs to CO for ethanol, a rarely quantified gas-phase trace gas, ranged from values similar to those previously reported, to up to
\end{abstract}

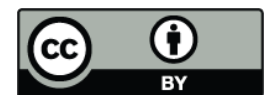

Correspondence to: R. S. Hornbrook (rsh@ucar.edu) an order of magnitude greater. Notably, though variable between plumes, observed NEMRs of individual light alkanes are highly correlated within BB emissions, independent of estimated plume ages. BB emissions of oxygenated NMOC were also found to be often well-correlated. Using the NCAR Master Mechanism chemical box model initialized with concentrations based on two observed scenarios, fresh Canadian BB and fresh Californian BB, decreases are predicted for the low molecular weight carbonyls (i.e. formaldehyde, acetaldehyde, acetone and methyl ethyl ketone, MEK) and alcohols (i.e. methanol and ethanol) as the plumes evolve in time, i.e. the production of these compounds is less than the chemical loss. Comparisons of the modeled NEMRs to the observed NEMRs from BB plumes estimated to be three days in age or less indicate overall good agreement.

\section{Introduction}

Biomass burning (BB) is a significant source of gases and particles to the regional and global atmosphere, playing an important role in the chemistry and radiative transfer of the atmosphere (Levine, 2000). Although the majority of BB occurs in the tropics, fires in extratropical regions can impact both local and regional air quality (Colarco et al., 2004; Morris et al., 2006), and contribute to climate change and the chemistry of polar atmospheres (Damoah et al., 2004; Vivchar et al., 2010; Tilmes et al., 2011). Due to convection and pyroconvection, BB plumes from boreal forests can inject trace gases and aerosols into the upper troposphere and

Published by Copernicus Publications on behalf of the European Geosciences Union. 
lower stratosphere, where long-range transport can widely and rapidly distribute the emissions (Fromm et al., 2000; Jost et al., 2004; Val Martin et al., 2010). Although there have been a number of laboratory studies of NMOC emissions from BB (Christian et al., 2003, 2004; Yokelson et al., 2008) as well as both near-field (Friedli et al., 2001; Jost et al., 2003; Sinha et al., 2003, 2004; Christian et al., 2007; Yokelson et al., 2007a, b, 2009) and long-range transport studies of fire plumes (Holzinger et al., 2005; de Gouw et al., 2006; Duck et al., 2007; Yuan et al., 2010), emissions of NMOCs from BB and the chemical evolution of these compounds within the plumes remain relatively uncertain (de Gouw et al., 2006; Monks et al., 2009). This is particularly true for emissions of oxygenated NMOC, as evidenced by the factor of 3.7 to 4.9 increase of NMOC emissions in a recent fire emissions inventory over previous inventories to account for additional oxygenated compounds, many of which are not quantitatively identified by presently-available observation methods (Wiedinmyer et al., 2011).

The 2008 NASA Arctic Research of the Composition of the Troposphere from Aircraft and Satellites (ARCTAS) mission was part of the broader International Polar Year (IPY) collaborative effort POLARCAT (Polar Study using Aircraft, Remote Sensing, Surface Measurements and Models, of Climate, Chemistry, Aerosols, and Transport). ARCTAS was a multi-platform field campaign involving airborne measurements from three NASA aircraft (DC-8, P-3B and B-200), a number of ground-based measurement sites and satellite observations. ARCTAS was held in coordination with other POLARCAT activities including the NOAA-led Aerosol, Radiation and Cloud Processes affecting Arctic Climate (ARCPAC) and the Greenland Aerosol and Chemistry Experiment (DLR-GRACE). An overview of the ARCTAS campaign has been published with a detailed description of all the measurement platforms and supporting investigations used during the campaign (Jacob et al., 2009). As well, an overview of the meteorology during ARCTAS and modeled back trajectories is available (Fuelberg et al., 2010).

The work in this paper and a following paper (Part 2) (Hornbrook et al., 2011) focus on measurements made on board the NASA DC-8 during ARCTAS. The DC- 8 was involved in the three major components of the ARCTAS campaign: (a) ARCTAS-A, based in Fairbanks, Alaska with research flights in the Arctic regions of Canada, Alaska and Greenland between 1-19 April 2008, (b) ARCTAS-CARB, based in Palmdale, California, in co-operation with the California Air Resources Board (CARB) with flights over California between 18-26 June 2008, and (c) ARCTAS-B, based in Alberta, Canada with flights over Central Canada and the Arctic regions of Canada and Greenland between 26 June13 July 2008. In total, there were 9 flights during the spring and 13 flights during the summer.

Objectives for the three ARCTAS components were specific to each region of study but sometimes overlapped, including long-range transport of pollution from mid-latitudes to the Arctic, ozone budgets, chemical processes, and aerosol radiative forcing. In both the spring and summer of 2008, there were a significant number of large-scale BB events in the Northern Hemisphere, including widespread boreal forest fires in Siberia, agricultural/grassland fires in Kazakhstan (Warneke et al., 2009) during April, coniferous forest, grass and brush fires in California and boreal forest fires in the Yukon and Saskatchewan in late June and July. As a result, all three ARCTAS components provided opportunities to study and characterize BB plumes. These plumes originated from a variety of source regions and ranged from fresh emissions to long-range transported plumes aged for up to a week or more. Because of competing objectives, the DC-8 instrument package was not optimized for investigating BB plumes and their evolution. However, with several instruments on board the DC-8 that measured the mixing ratios of a vast number of NMOCs, along with a suite of other trace gas measurements, the ARCTAS flights provided a valuable data set for investigating NMOCs in several different BB plumes.

In this paper (Part 1), an overview of the NMOC observations is presented, including a comparison of the observations from the different NMOC measurement techniques used on board the DC- 8 during ARCTAS. Flight time intervals when the DC-8 sampled air masses influenced by BB were identified using known fire tracers; aircraft coordinates, back trajectories, and MODIS fire counts were used to determine the origin of each plume. These identified BB interceptions were grouped by flight, source region and time-of-day into 40 plumes for analysis. The relative enhancements of individual NMOCs to longer-lived fire tracer species were determined for each group, analyzed with regards to estimated BB plume age, and compared with previously-observed NEMRs. In Part 2, BB emissions observed from different source regions during ARCTAS are contrasted with urban emissions and anthropogenic point sources also sampled during the study.

\section{Experimental}

\subsection{Aircraft measurements}

The Trace Organic Gas Analyzer (TOGA) uses fast online gas chromatography coupled with mass spectrometry (GS-MS), analyzing a 40-s integrated sample once every two minutes, and was used to measure up to 28 different NMOCs during ARCTAS. Major instrument components of the TOGA include the heated electropolished stainless steel (SS) inlet, cryogenic preconcentrator, gas chromatograph (GC), mass spectrometer (MS), and zero air/calibration system. All processes and data acquisition are computer controlled. The instrument has been described previously by Apel et al. (2003, 2010). Three traps are used: a water trap, an enrichment trap packed with glass wool, and a cryofocusing trap, with no adsorbents in any of the traps. The 
GC is a custom-designed unit that is lightweight and temperature programmable, fitted with a Restek MTX-624 column (I.D. $=0.18 \mu \mathrm{m}$, length $=8 \mathrm{~m}$ ). Detection limits are compound dependent but range from sub-pptv (parts per trillion by volume) to $20 \mathrm{pptv}$. The system was calibrated with an in-house gravimetrically-prepared mixture containing 25 of the targeted 28 compounds. Post-mission calibrations were performed to obtain response factors for the three compounds not in the standard. The calibration mixture was dynamically diluted with scrubbed ambient (outside aircraft) air to mixing ratios near typically-observed levels.

The 28 NMOCs observed by TOGA during ARCTAS include NMHC (nonmethane hydrocarbons; $\mathrm{C}_{4}$ and $\mathrm{C}_{5}$ alkanes, isoprene, benzene, toluene, the $\mathrm{C}_{8}$ aromatic hydrocarbons), oxygenated NMOCs (acetaldehyde $\left(\mathrm{CH}_{3} \mathrm{CHO}\right)$, methanol $\left(\mathrm{CH}_{3} \mathrm{OH}\right)$, ethanol $\left(\mathrm{C}_{2} \mathrm{H}_{5} \mathrm{OH}\right)$, acetone $\left(\mathrm{CH}_{3} \mathrm{COCH}_{3}\right)$, propanal $\left(\mathrm{C}_{2} \mathrm{H}_{5} \mathrm{CHO}\right)$, methacrolein (MACR; $\mathrm{CH}_{2} \mathrm{C}\left(\mathrm{CH}_{3}\right) \mathrm{CHO}$ ), methyl vinyl ketone (MVK; $\left.\mathrm{CH}_{2} \mathrm{CHCOCH}_{3}\right)$, butanal $\left(\mathrm{C}_{3} \mathrm{H}_{7} \mathrm{CHO}\right)$, MEK $\left(\mathrm{C}_{2} \mathrm{H}_{5} \mathrm{COCH}_{3}\right)$ methyl tert-butyl ether (MTBE; $\left.\mathrm{C}\left(\mathrm{CH}_{3}\right)_{3} \mathrm{OCH}_{3}\right)$ ), halogenated NMOCs (chloromethane $\left(\mathrm{CH}_{3} \mathrm{Cl}\right)$, bromomethane $\left(\mathrm{CH}_{3} \mathrm{Br}\right)$, dichloromethane $\left(\mathrm{CH}_{2} \mathrm{Cl}_{2}\right)$, chloroform $\left(\mathrm{CHCl}_{3}\right)$, tetrachloromethane $\left(\mathrm{CCl}_{4}\right)$ ), acetonitrile $\left(\mathrm{CH}_{3} \mathrm{CN}\right)$ and dimethylsulfide (DMS; $\mathrm{CH}_{3} \mathrm{SCH}_{3}$ ). The list of species quantified by TOGA during ARCTAS was established by a number of criteria including being relevant to the ARCTAS objectives, complementary to other measurements, reliably separable and observable, and for which calibrations are well-established.

In addition to the TOGA, two other instruments on board the DC- 8 measured some of the above NMOCs as well as additional NMOC mixing ratios: a proton-transfer-reaction mass spectrometer (PTR-MS) and a whole air sampler (WAS). Recently, de Gouw and Warneke (2007) reviewed the use of PTR-MS for measurements of NMOCs in the Earth's atmosphere. During ARCTAS, the University of Innsbruck PTR-MS routinely measured methanol $\left(\mathrm{m} / z 33^{+}\right.$; $\mathrm{m} / \mathrm{z}$ being the mass-to-charge ratio of the detected protonated ion), acetonitrile $\left(\mathrm{m} / \mathrm{z}, 42^{+}\right)$, acetaldehyde $\left(\mathrm{m} / z 45^{+}\right)$, acetone $\left(\mathrm{m} / 259^{+}\right)$, the sum of isoprene and furan $\left(\mathrm{C}_{4} \mathrm{H}_{4} \mathrm{O}\right)$ $\left(\mathrm{m} / z 69^{+}\right)$, the sum of MVK and MACR $\left(\mathrm{m} / z 71^{+}\right)$, benzene $\left(\mathrm{m} / \mathrm{z} 79^{+}\right)$and toluene $\left(\mathrm{m} / \mathrm{z} 93^{+}\right)$. 0.5-to- $1 \mathrm{~s}$ average mixing ratios were reported approximately once each 5-10 s for most compounds. Although previous studies have included a wider range of species quantified by PTR-MS, the system was included on the DC-8 to provide high time resolution NMOC data in the 10- to 20-s range, which is not sufficient time to provide full mass scans. Thus, a sub-set of signals was selected for which the PTR-MS method has been wellvalidated in the past. Due to a poorer signal-to-noise ratio, PTR-MS acetaldehyde mixing ratios were reported as 1-min averages. Periodic pre-flight and in-flight calibrations were performed using a NMOC gas standard (prepared by AiR Environmental, Inc., Broomfield, CO) containing approximately 1 ppmv (parts per million by volume) of all target compounds (except furan and methacrolein) in compressed nitrogen (accuracy: $\pm 5 \%$ ). The standard gas was dynamically diluted to ppbv (parts per billion by volume) levels. For zeroing, the PTR-MS inlet flow was periodically diverted through a heated $\mathrm{Pt} / \mathrm{Pd}$ catalyst.

Described in detail by Simpson et al. (2011), whole air samples were collected during the flights through a forward facing non-heated SS inlet (1/4 in.) into electropolished SS flasks and pressurized to $40 \mathrm{psig}$ with a metal bellows pump (Senior Flexonics, MB 602). 168 canisters were available for each flight. The canister sampling frequency varied depending on location and altitude, and was typically a 1-min integrated sample every $3-5$ min during horizontal flight legs, and every 1-2 min during vertical profiles and plume encounters. Above $9 \mathrm{~km}$ above sea level (ASL), the sample integration period increased with increasing altitude to $>120 \mathrm{~s}$ above $11 \mathrm{~km}$ ASL. The filled canisters were transported back to the University of California, Irvine (UCI) laboratory and analyzed by gas chromatography (GC) within 7 days of collection for 79 trace gases comprising NMHCs, halocarbons, DMS, alkyl nitrates, and oxygenated NMOCs. Five columns and three detection methods were used: mass spectrometry (MS), flame ionization detection (FID), and electron capture detection (ECD). The reported detection limits are $3 \mathrm{pptv}$ for most NMHC, 5 pptv for MVK and MACR, and 20, 50, and $100 \mathrm{pptv}$ for ethanol, methanol, and acetone, respectively. All NMHCs were calibrated against whole air working standards, which had been calibrated against NIST and Scott Specialty Gases standards. The precision of the $\mathrm{C}_{2}-\mathrm{C}_{4}$ NMHC analysis was $\pm 3 \%$ when compared to NIST standards during the Nonmethane Hydrocarbon Intercomparison Experiment (NOMHICE) (Apel et al., 1994, 1999). Further details are given by Colman et al. (2001) and Simpson et al. (2010).

Measurements of other gas-phase species of interest to BB studies included hydrogen cyanide ( $\mathrm{HCN})$, formaldehyde $\left(\mathrm{CH}_{2} \mathrm{O}\right)$, carbon monoxide $(\mathrm{CO})$ and carbon dioxide $\left(\mathrm{CO}_{2}\right)$. $\mathrm{HCN}$ was quantified in integrated 0.5 -s sampling every $15 \mathrm{~s}$ by chemical ionization mass spectrometry (CIMS) via reaction with $\mathrm{CF}_{3} \mathrm{O}^{-}$directly in sampled ambient air and monitoring the product ion $m / z=112$. Other corrections for the sensitivity are made by in-flight standard addition calibrations of $\mathrm{H}_{2} \mathrm{O}_{2}$ and $\mathrm{HNO}_{3}$, also measured by the same CIMS system (Crounse et al., 2006) and proxied to laboratory calibrations of $\mathrm{HCN}$. The detection limit $(\mathrm{S} / \mathrm{N}=1)$ is better than $15 \mathrm{pptv}$ for moderate to low water vapor levels $\left(\mathrm{H}_{2} \mathrm{O}\right.$ mixing ratio $\leq 0.004$ ) (Crounse et al., 2009). $\mathrm{CH}_{2} \mathrm{O}$ observations were made using difference frequency generation (DFG) absorption Spectroscopy (DFGAS). This technique has been discussed by Weibring et al. (2006, 2007). Briefly, ambient air, continuously sampled through a heated $\left(35^{\circ} \mathrm{C}\right) \frac{1}{2}^{\prime \prime}$ O.D. PFA Teflon line extending into the free air stream outside the aircraft, was directed through an astigmatic multipass (100-m optical pathlength) Herriott absorption cell 
maintained at 50 Torr pressure. Mid-Infrared laser light at $2831.6 \mathrm{~cm}^{-1}(3.53 \mu \mathrm{m})$, which hits a moderately strong and isolated vibrational-rotational feature of $\mathrm{CH}_{2} \mathrm{O}$, was generated by mixing two near-IR room temperature lasers in a non-linear crystal. Ambient $\mathrm{CH}_{2} \mathrm{O}$ mixing ratios were determined by fitting sample absorption spectra to calibration spectra employing onboard permeation calibration standards. Typical $\mathrm{CH}_{2} \mathrm{O}$ detection limits $(2 \sigma)$ were around $25 \mathrm{pptv}$ for one-minute averages. $\mathrm{CO}$ observations were made using a diode laser spectrometer and reported at $1 \mathrm{~Hz}$ using the method described by Sachse et al. (1988). $\mathrm{CO}_{2}$ observations were made with a non-dispersive IR analyzer described previously (Vay et al., 2003) and were also reported at $1 \mathrm{~Hz}$. All observed data from the ARCTAS study are publicly available at http://www-air.larc.nasa.gov.

\subsection{Model}

The NCAR Master Mechanism (MM) was used to simulate the chemical evolution of observed NMOCs within BB plumes, and to contrast the chemistry between BB plumes originating from a region highly influenced by anthropogenic activities and one that is largely devoid of anthropogenic influence. The Master Mechanism is a 0-D model with detailed gas-phase chemistry consisting of approx. 5000 reactions among approx. 2000 chemical species combined with a box model solver (Madronich and Calvert, 1990; Madronich, 2006) and has been used previously to investigate oxygenated NMOC within BB plumes (Mason et al., 2001, 2006). Constrained inputs may include species of interest, emissions and temperature. The model computes the time-dependent chemical evolution of an air parcel initialized with known composition. For these model runs, no additional emissions, dilution or heterogeneous processes were included. Photolysis rates are calculated using the Tropospheric Ultraviolet-Visible (TUV) model (Madronich and Flocke, 1999).

\section{Results and discussion}

\subsection{Comparisons of NMOC measurements}

ARCTAS was the first study in which TOGA and PTR-MS measurements were made on board the DC- 8 , and there was significant overlap between the NMOCs observed by TOGA and those measured by PTR-MS and/or WAS during the campaign. To accommodate the different sampling frequencies of the many instruments on the DC-8, several time-base merges of the reported data were generated in which reported observations were averaged over specific timescales, including a 1-min merge, a 1-s merge, a TOGA merge and a WAS merge. For the TOGA merge, observations with sampling times that overlapped with the TOGA sampling period were averaged to the timescale of the reported TOGA observations. Likewise, for the WAS merge, observations with sam- pling times that overlapped with the whole air samples were averaged to the timescale of the reported WAS observations. Further details on how these merges are generated are discussed by Kleb et al. (2011). In this work, individual data point comparisons between reported TOGA observations and reported PTR-MS and WAS observations were made using the TOGA merge.

Comparison plots of the mixing ratios of compounds reported by both TOGA and PTR-MS during ARCTAS-A, -CARB and -B are shown in Fig. 1. Likewise, similar plots for many of the NMOCs measured by both TOGA and WAS are shown in Fig. 2. The solid lines in the plots in Figs. 1 and 2 are orthogonal distance regression (ODR) fits to the data, with slope and intercept shown on each plot. The $r^{2}$ value for the standard linear regression fit to the data is included on each plot, to provide further information on the goodness of fit. The dotted lines in each plot show $y=x$ for comparison. Most compounds reported by both TOGA and PTR-MS show good agreement, with all ODR slopes within \pm 0.15 of unity, and most $r^{2}$ values at 0.85 or greater. For isoprene, because the reported PTR-MS data includes furan, a compound with elevated mixing ratios in BB plumes, the ODR fit shown on the isoprene comparison plot excluded data points identified as BB (see Sect. 3.2). Isoprene data identified as BB are shown on the isoprene plot in Fig. 1 (black circles), and clearly indicate that in BB plumes, the majority of PTR-MS isoprene + furan data are larger than the TOGA isoprene data. Using only data attributed to BB, an ODR of the TOGA isoprene against the PTR-MS $m / z 69^{+}$signal indicates that, on average, $(47 \pm 2) \%$ of the PTR-MS signal is isoprene, which is consistent with the average isoprene ratio in laboratory fires of $48 \%$ given by Karl et al. (2007). Similarly, from a comparison against the WAS isoprene and furan data attributed to BB, ODR fits to the $m / z 69^{+}$signal indicate that the PTR-MS signal is split on average into isoprene $(39 \pm 3) \%$, furan $(45 \pm 2) \%$, and $(16 \pm 5) \%$ other compounds, but it should be noted that the uncertainty of the furan data from the canisters is relatively high with reported accuracy $\pm 20 \%$ and precision $\pm 30 \%$.

The scatter in the acetonitrile plot in Fig. 1 is a little greater than that of the other compounds, with an $r^{2}$ of 0.73 for the standard linear regression fit, but with an ODR slope of $0.932 \pm 0.008$, the agreement between the instruments is still very good. For some NMOCs, the reported mixing ratios deviate at higher mixing ratios, with larger values reported from the PTR-MS measurement than by the TOGA measurement, in particular for acetonitrile and to a lesser extent methanol, acetone and the combined MVK + MACR. There are also deviations between the TOGA and PTR-MS at very low mixing ratios $(<10 \mathrm{pptv})$ for toluene, benzene and acetaldehyde, with TOGA generally reporting slightly lower mixing ratios.

Good agreement is also observed between the results from TOGA and WAS for most NMOCs (Fig. 2), with the majority of the ODR fits having slopes within \pm 0.20 of unity and $r^{2}$ values of 0.80 or greater. Exceptions to 

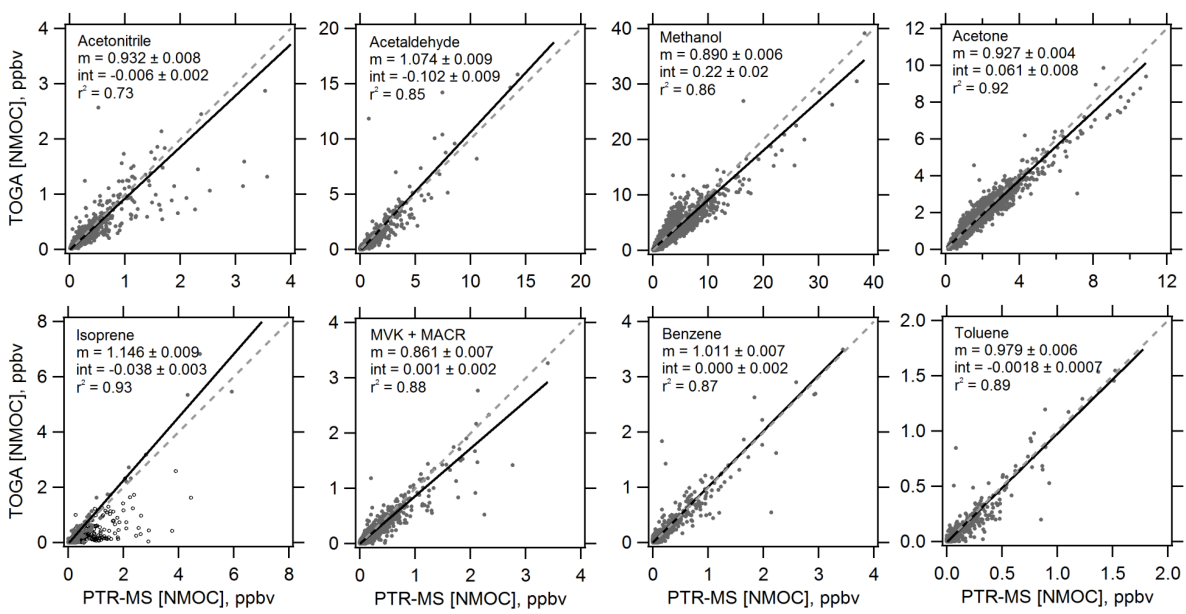

Fig. 1. Comparisons between all ARCTAS TOGA and PTR-MS observations for co-measured NMOCs. Solid lines are ODR fits to the data, with slope and intercept (with $1 \sigma$ standard deviations) shown on each plot. Dashed lines show $y=x$. As well, the $r^{2}$ value for the standard linear-regression best-fit has been included on each plot. For isoprene, only data identified as non-BB (grey points, i.e.: not listed in Table 1) are used for the ODR, as PTR-MS isoprene is reported as a sum with furan, which is present in BB. BB data are shown as black circles; using all ARCTAS isoprene data including BB data, the ODR fit has slope $0.76 \pm 0.01$ and intercept $-0.036 \pm 0.006 \mathrm{ppbv}$.
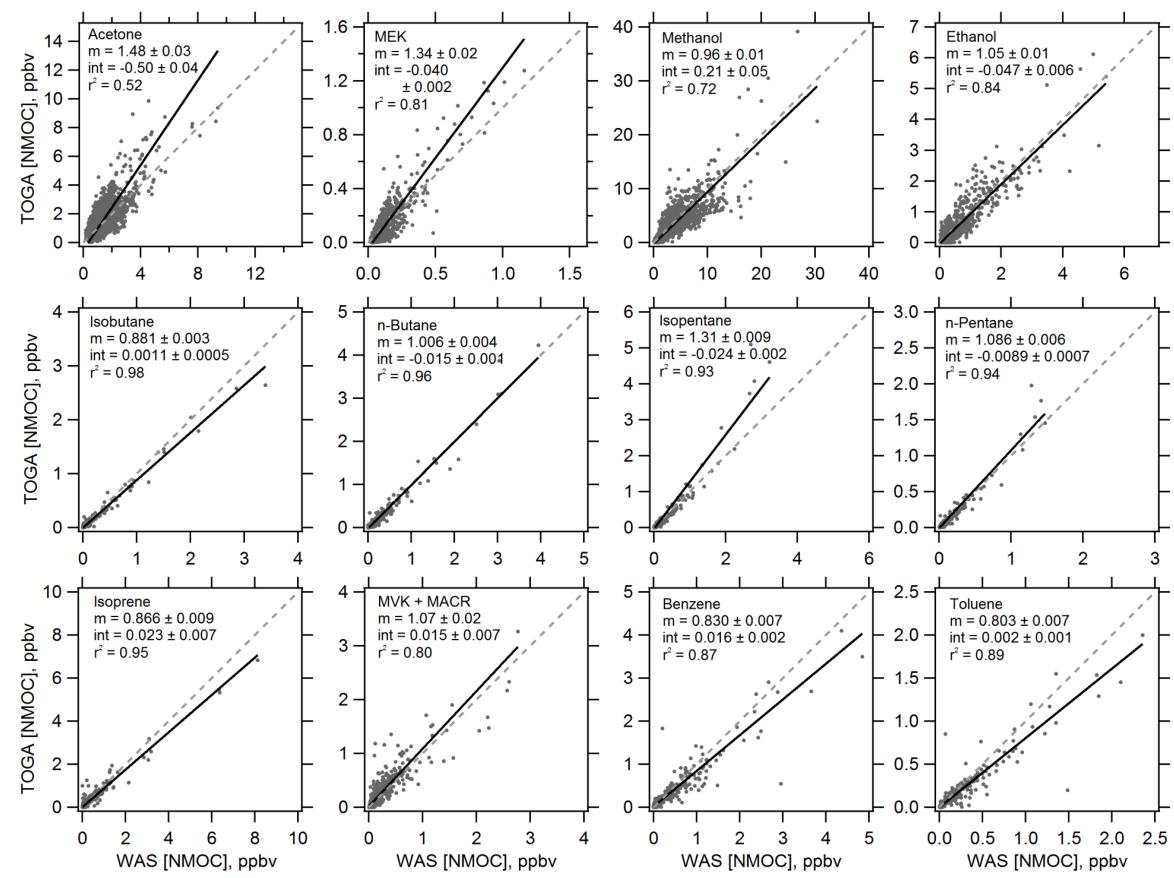

Fig. 2. Comparisons between ARCTAS TOGA and WAS observations for selected co-measured NMOCs, similar to Fig. 1.

this include acetone (slope $1.48 \pm 0.03 ; r^{2}=0.52$ ), methanol (slope $=0.96 \pm 0.01 ; r^{2}=0.72$ ), MEK (slope $1.34 \pm 0.02$; $r^{2}=0.81$ ) and isopentane (slope $1.31 \pm 0.09 ; r^{2}=0.93$ ). For acetone, MEK and isopentane, the TOGA mixing ratios at higher concentrations are larger than those from the WAS system. This is in contrast to the benzene and toluene results, with the TOGA mixing ratios on average $21.5 \%$ and $23.2 \%$ lower, respectively, than those from WAS. However, overall the TOGA mixing ratios for benzene and toluene agreed well with the PTR-MS values, with slopes of $1.011 \pm 0.007$ and $0.979 \pm 0.006$, respectively. Although the oxygenated NMOCs measured by TOGA and WAS compare reasonably well on average, the spread in some of the comparison plots is greater than most of the other plots in Figs. 1 and 2, 
including those for oxygenated NMOCs observed by TOGA and PTR-MS. This is consistent with reported higher uncertainties for canister measurements of oxygenated NMOCs, based on the knowledge that these species can either increase or decrease in the canisters at a rate of a few percent per day (Simpson et al., 2011).

The majority of the NMOC observations from ARCTAS are at background or near-background mixing ratios, with many of the largest mixing ratios from encounters with fresh $\mathrm{BB}$ emissions. Because of the non-uniformity of gases in fresh fire plumes and the limited spatial extent of the plumes, the different integrated sampling times of the instruments contribute significantly to the differences in larger mixing ratios. An example of how sampling integration time impacts NMOC measurements is shown in Fig. 3, a time-series plot of the benzene observations from a section of the 4 July 2008 flight in which the DC-8 sampled two narrow smoke plumes followed by a wider smoke plume. TOGA, PTR-MS and WAS benzene measurements are plotted according to their reported measurement timescales along with the 1-s [CO] observations and the 1-min merge GPS altitude. For the WAS and TOGA measurements, the bars indicate the start and stop times of the integrated sampling. For the WAS system, the sampling flow rate is variable, with higher flow rates into the evacuated canisters at the beginning of the sampling interval, and lower flow rates towards the end as the target fill pressure is reached. The flow rate for the TOGA sampling is controlled at a constant volumetric flow of $50 \mathrm{sccm}$ (standard cubic centimeters per minute). Included on the plot are the TOGA-merge values for the PTR-MS and WAS measurements. In the first narrow plume at approximately 02:00:30 UTC, both the TOGA and WAS systems observed benzene mixing ratios well above the background concentrations. However, because the integrated sampling time for the WAS measurement was longer than that of the TOGA, it also included some of the background air (indicated by low $[\mathrm{CO}]$ ) and the resulting WAS-reported benzene mixing ratio is lower than that reported by TOGA and PTR-MS. During the next narrow plume, the timing of WAS captured the plume, while TOGA sampled before and after, missing the narrow plume altogether. Here, the WAS measurement is not included in the TOGA merge because there was no overlap in the integrated sampling times. However in a very structured air mass, an overlap in the sampling periods could result in very different concentrations being compared side-by-side in the TOGA merge. This is seen in the TOGA-merge data at 02:12:30 in which the WAS benzene mixing ratio is more than double those of TOGA and PTR-MS. Here the WAS observation included a portion of a large plume and background air, and the TOGA measurement was primarily background air, hence the TOGA-merge WAS [benzene] is more than double that of TOGA and PTR-MS measurements. Because of these differences, where possible, many of the analyses in this work were performed on the observations from more than one NMOC measurement technique to eliminate

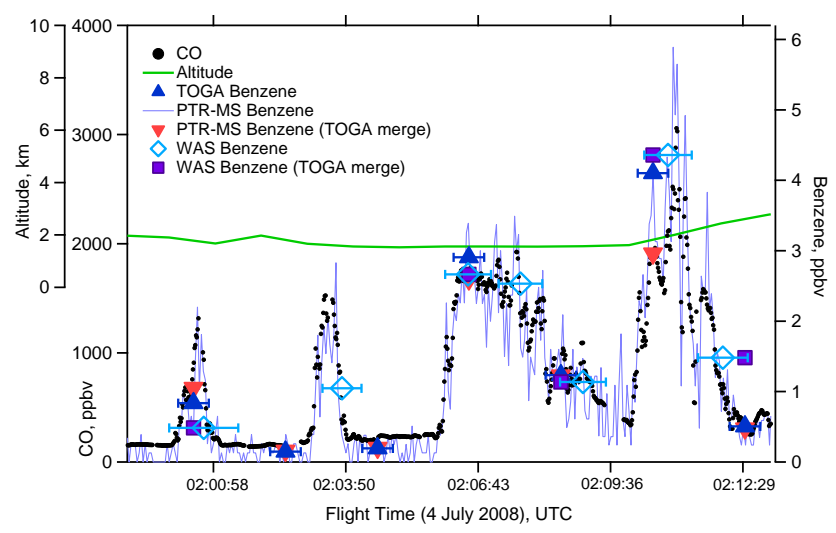

Fig. 3. Time series plot of CO, benzene observations and TOGAmerge values for benzene during a section of the 4 July 2008 ARCTAS DC-8 flight. Error bars show the start and stop times of the WAS and TOGA integrated sampling periods.

bias from individual techniques. With the exception of acetaldehyde, due to the longer PTR-MS averaging period, no sampling bias is expected for the comparison of TOGA and PTR-MS measurements using the TOGA-merge, as the PTRMS observations are integrated within the TOGA sampling period.

\subsection{Biomass burning plume identification}

Maps of MODIS fire counts in Asia and North America in (a) April 2008 and (b) June and July 2008 are shown in Fig. 4. During both the spring and summer ARCTAS deployments, the DC-8 sampled air masses originating from the regions with strong BB emissions (Fuelberg et al., 2010). For this analysis, interceptions of fire emissions by the DC-8 were identified by elevated mixing ratios of $\mathrm{CH}_{3} \mathrm{CN}, \mathrm{HCN}$ and $\mathrm{CO}$. HCN has been identified as a BB tracer (Lobert et al., 1990; Shim et al., 2007). $\mathrm{CH}_{3} \mathrm{CN}$ has been also identified as an indicator of $\mathrm{BB}$ emissions that is not significantly enhanced in urban areas of the United States where other anthropogenic tracers are elevated (de Gouw et al., 2003 , 2006). Because background mixing ratios of $\mathrm{CH}_{3} \mathrm{CN}$, $\mathrm{HCN}$ and $\mathrm{CO}$ are not constant throughout the regions covered during ARCTAS, plume identification was done using the 1-min and TOGA merges, identifying time periods with elevated fire tracer mixing ratios above the local background. Generally, "elevated" refers to $\mathrm{CH}_{3} \mathrm{CN}$ mixing ratios $>200$ pptv, HCN mixing ratios $>400$ pptv, and CO mixing ratios $>175 \mathrm{ppbv}$, but in regions with lower background mixing ratios, long-range BB plumes with lower threshold mixing ratios were also sometimes identifiable above the background. Air masses sampled in urban regions with both elevated fire tracers and strongly-enhanced anthropogenic tracers (e.g. toluene, $\mathrm{NO}_{\mathrm{x}}$ ) were not included in this analysis to provide a more precise analysis of only biomass burning emissions and enhancements. 


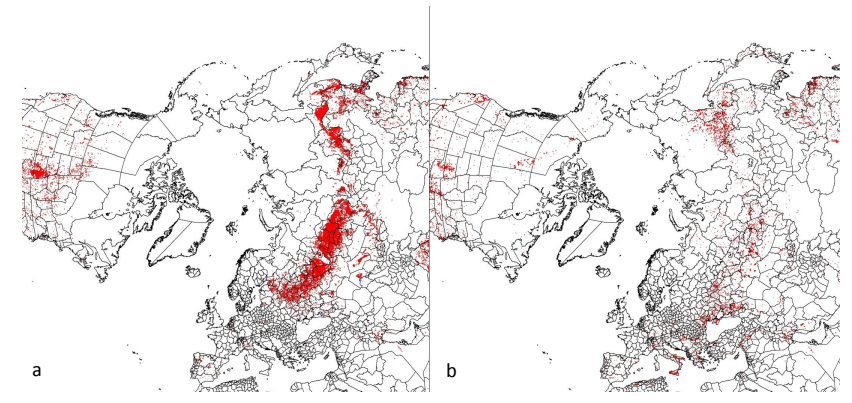

Fig. 4. Plot of the MODIS fire counts in the Northern Hemisphere during (a) April 2008 and (b) June-July 2008.

Figure 5 is a map of the DC- 8 flights from ARCTAS-A, -B and -CARB over North America, with identified BB interceptions colored by the approximated age of each plume. Periods of BB sampling lasting between two minutes and two hours were attributed to different source regions using back trajectories and local fire information. Smoke interceptions from individual flights were then grouped together first by source region but also based on similar coincident ratios of several NMOC to $\mathrm{CO}$ and on estimated ages, generating a total of 40 identified BB plumes from 15 flights. For many of the Asian BB interceptions, this meant that fire plumes from a wider source region were sometimes grouped together to generate sufficient statistics required for analysis. For some of the Canadian and Californian fires, smoke plumes sampled at several locations including close to and at different locations downwind of the fire were analyzed separately due to significant changes that had occurred chemically within the plumes, either due to changing emissions or changing enhancements of NMOC with respect to CO.

The average age of each of the 40 plumes was estimated based on back trajectories, aircraft altitude, local fire information, proximity to the fires being observed and the duration of the smoke sampling by the aircraft. These estimated ages are merely approximations and are meant to easily differentiate between plumes that include very fresh BB emissions and plumes in which the fire emissions are aged 23 days or up to a week or more. Thus, the uncertainties of the estimated plume ages should be considered to be approximately $\pm 50 \%$.

The modified combustion efficiency (MCE) of a smoke plume, defined as $\Delta \mathrm{CO}_{2} /\left(\Delta \mathrm{CO}_{2}+\Delta \mathrm{CO}\right)$ (Ward and Radke, 1993) where $\Delta$ indicates an excess mixing ratio from the background, is an indicator of the relative abundance of flaming and smoldering combustion within a fire. An MCE of 0.99 indicates pure flaming combustion, while MCEs between 0.65 and 0.85 are considered to indicate pure smoldering combustion, and MCEs between 0.85 and 0.99 indicate a mixture of flaming and smoldering (Akagi et al., 2011). For each BB plume, the MCE was determined from coincident observations of $\mathrm{CO}$ and $\mathrm{CO}_{2}$. The plume emission

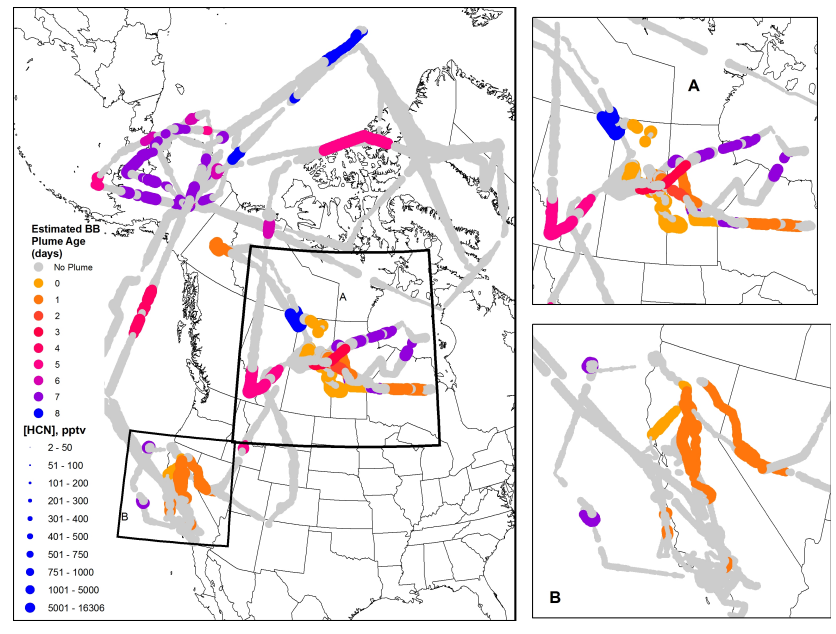

Fig. 5. Map of the plume interceptions on all the DC- 8 flight paths during ARCTAS. Colored points indicate plume interceptions according to the upper legend, with estimated BB plume ages based on back trajectories, altitude, and location relative to local fires. Points are sized according to the reported $\mathrm{HCN}$ mixing ratio, as indicated in the lower legend. Detail map A is an expanded map showing the ARCTAS-B flights over central Canada, and detail map B is an expanded map showing the ARCTAS-CARB flights over California.

ratio $\Delta \mathrm{CO} / \Delta \mathrm{CO}_{2}$ was determined from an ODR fit of the 1-s merge $\mathrm{CO}$ and $\mathrm{CO}_{2}$ data, and the rearranged relationship $\mathrm{MCE}=1 /\left[\left(\Delta \mathrm{CO} / \Delta \mathrm{CO}_{2}\right)+1\right]$ was used to calculate the MCE. The uncertainty of the MCE was determined using the standard error in the ODR fit to the $\mathrm{CO}$ versus $\mathrm{CO}_{2}$ data. A summary of the $40 \mathrm{BB}$ plumes with flight times during which the plumes were sampled, source region, estimated average plume age, and MCE is listed in Table 1. For some of the plumes observed over California, the coincident observations of $\mathrm{CO}$ and $\mathrm{CO}_{2}$ did not correlate over the time period(s), and thus the MCEs could not be determined. As well, for several plumes observed during ARCTAS-B, the observed $\mathrm{CO}$ and $\mathrm{CO}_{2}$ were inversely correlated, leading to nonsensical MCEs > 1, which cannot be a true reflection of the emissions, and thus these MCEs were not reported in Table 1 . The MCE for plume 28 , however, is still realistically 1 within its uncertainty, and has been included.

\subsection{NMOC enhancements in biomass burning plumes}

Commonly used to quantify the atmospheric impact of BB, emission ratios or enhancement ratios can be determined for trace gases emitted from BB or produced in a BB plume as it ages. An emission ratio (ER) is the molar ratio between two emitted compounds measured at a fire source, and is generally reported as $\Delta[X] / \Delta[Y]$ where $\Delta[X]$ and $\Delta[Y]$ refer to excess mixing ratios of the two species in the smoke minus the mixing ratio of those species in background air. $Y$ can be any emitted compound, but is generally a longlived smoke tracer such as $\mathrm{CO}$ or $\mathrm{CO}_{2}$. By definition, ERs 
Table 1. Summary of Biomass Burning Plume Encounters.

\begin{tabular}{|c|c|c|c|c|c|}
\hline Plume & $\begin{array}{l}\text { Flight } \\
\text { Date }\end{array}$ & $\begin{array}{l}\text { Plume Interception } \\
\text { Times (UTC) }{ }^{\mathrm{a}}\end{array}$ & $\begin{array}{l}\text { Biomass Burning } \\
\text { Plume Origin }\end{array}$ & $\begin{array}{l}\text { Plume } \\
\text { Age, } \\
\text { Days }^{\mathrm{a}}\end{array}$ & $\begin{array}{l}\text { Modified } \\
\text { Combustion } \\
\text { Efficiency }^{b}\end{array}$ \\
\hline 1 & $12 \mathrm{Apr}$ & $16: 15-16: 24 ; 16: 39-16: 58 ; 17: 07-17: 14$ & Asia & 7 & $0.982 \pm 0.004$ \\
\hline 2 & $12 \mathrm{Apr}$ & $17: 40-18: 00$ & Asia & 5 & $0.97 \pm 0.01$ \\
\hline 3 & $12 \mathrm{Apr}$ & 19:05-19:18; 20:04-20:12 & Asia & 6 & $0.98 \pm 0.01$ \\
\hline 4 & $12 \mathrm{Apr}$ & $21: 52-23: 00$ & Asia & 7 & $0.983 \pm 0.007$ \\
\hline 5 & $16 \mathrm{Apr}$ & $\begin{array}{l}20: 16-20: 27 ; 22: 57-23: 08 ; 23: 20-23: 39 \\
00: 02-00: 45 ; 00: 56-01: 00 ; 01: 02-01: 25 \\
01: 46-01: 50 ; 02: 05-02: 11\end{array}$ & Siberia & 7 & $0.979 \pm 0.006$ \\
\hline 6 & $16 \mathrm{Apr}$ & $22: 33-22: 43$ & Alaska & 4.5 & $0.986 \pm 0.009$ \\
\hline 7 & $17 \mathrm{Apr}$ & $20: 22-20: 27 ; 21: 04-21: 21$ & Siberia & 6 & $0.97 \pm 0.02$ \\
\hline 8 & $17 \mathrm{Apr}$ & $22: 05-22: 20$ & Alaska & 8 & $0.97 \pm 0.03$ \\
\hline 9 & $17 \mathrm{Apr}$ & $\begin{array}{l}23: 40-23: 44 ; 00: 53-01: 08 ; 01: 13-01: 45 \\
02: 00-02: 10 ; 02: 40-02: 50\end{array}$ & Western Asia & 7.5 & $0.98 \pm 0.01$ \\
\hline 10 & $17 \mathrm{Apr}$ & 03:56-04:02; 04:53-05:04; 05:22-05:36 & Southern Asia & 7 & $0.97 \pm 0.03$ \\
\hline 11 & $19 \mathrm{Apr}$ & $20: 10-20: 41 ; 20: 52-21: 13$ & East Asia & 4 & $0.960 \pm 0.005$ \\
\hline 12 & 18 Jun & $18: 27-18: 30 ; 18: 38-18: 41$ & California & 1 & $0.91 \pm 0.02$ \\
\hline 13 & $20 \mathrm{Jun}$ & $19: 52-19: 54 ; 21: 35-21: 40$ & California & 0.2 & $0.90 \pm 0.03$ \\
\hline 14 & $20 \mathrm{Jun}$ & 00:01-00:02; 00:19-00:30 & California & 0.2 & $0.915 \pm 0.004$ \\
\hline 15 & 22 Jun & $18: 20-18: 28 ; 19: 41-19: 48$ & Asia & 7 & $0.96 \pm 0.04$ \\
\hline 16 & 22 Jun & $21: 08-21: 12 ; 21: 23-21: 44$ & California & 0.1 & - \\
\hline 17 & 24 Jun & $22: 12-22: 31$ & California & 1.5 & $0.90 \pm 0.03$ \\
\hline 18 & 26 Jun & $14: 32-14: 35 ; 15: 34-16: 17 ; 16: 39-16: 57$ & California & 1 & $0.88 \pm 0.01$ \\
\hline 19 & 29 Jun & $16: 04-16: 11 ; 21: 22-21: 49$ & Siberia & 5 & - \\
\hline 20 & 29 Jun & $18: 11-19: 22$ & Yukon & 1 & $0.91 \pm 0.04$ \\
\hline 21 & 29 Jun & $21: 56-22: 22 ; 22: 31$ & Saskatchewan & 0.1 & $0.918 \pm 0.009$ \\
\hline 22 & $1 \mathrm{Jul}$ & $20: 15-22: 00$ & Saskatchewan & 0.1 & $0.920 \pm 0.005$ \\
\hline 23 & $1 \mathrm{Jul}$ & $\begin{array}{l}22: 01-22: 23 ; 22: 29-22: 30 ; 22: 33-23: 58 \\
00: 15-00: 20\end{array}$ & Saskatchewan & 0.3 & $0.835 \pm 0.009$ \\
\hline 24 & $1 \mathrm{Jul}$ & 01:43-02:16; 02:19-02:49 & Saskatchewan & 0.1 & $0.82 \pm 0.01$ \\
\hline 25 & 4 Jul & $18: 20-18: 28$ & Saskatchewan & 0.1 & $0.83 \pm 0.04$ \\
\hline 26 & 4 Jul & $18: 45-18: 51 ; 19: 26-19: 45 ; 20: 23-20: 37$ & California & 3 & $0.92 \pm 0.08$ \\
\hline 27 & $4 \mathrm{Jul}$ & $\begin{array}{l}19: 00-19: 25 ; 22: 26-22: 52 ; 23: 56-0: 07 \\
00: 26-00: 56 ; 01: 16-01: 33\end{array}$ & Saskatchewan & 0.5 & - \\
\hline 28 & 4 Jul & $19: 52-20: 22$ & Saskatchewan & 0.1 & $1.01 \pm 0.01$ \\
\hline 29 & 4 Jul & $20: 54-21: 29 ; 22: 12-22: 19$ & Mixed Sask./Calif. & 1 & $0.92 \pm 0.03$ \\
\hline 30 & $4 \mathrm{Jul}$ & $01: 58-02: 32$ & Saskatchewan & 1 & $0.84 \pm 0.04$ \\
\hline 31 & $5 \mathrm{Jul}$ & $20: 41-20: 59$ & Saskatchewan & 1 & $0.93 \pm 0.04$ \\
\hline 32 & $5 \mathrm{Jul}$ & $21: 06-21: 22$ & Mixed Sask./Calif. & 2 & - \\
\hline 33 & $5 \mathrm{Jul}$ & $\begin{array}{l}23: 37-23: 58 ; 01: 03-01: 15 ; 01: 19-01: 37 \\
01: 43-01: 54\end{array}$ & Saskatchewan & 1 & - \\
\hline 34 & $5 \mathrm{Jul}$ & $02: 05-02: 30$ & Saskatchewan & 1 & - \\
\hline 35 & $8 \mathrm{Jul}$ & 09:19-09:31; 09:39-10:28 & Asia & 5 & - \\
\hline 36 & $8 \mathrm{Jul}$ & $12: 48-13: 04$ & Asia & 8 & - \\
\hline 37 & $8 \mathrm{Jul}$ & 14:59-16:08 & Asia & 5 & - \\
\hline 38 & $13 \mathrm{Jul}$ & $18: 31-18: 38$ & East Asia & 5 & - \\
\hline 39 & $13 \mathrm{Jul}$ & 19:34-20:26; 20:32-21:01 & California & 0.5 & $0.95 \pm 0.01$ \\
\hline 40 & $13 \mathrm{Jul}$ & $21: 02-21: 44$ & California & 0.5 & - \\
\hline
\end{tabular}

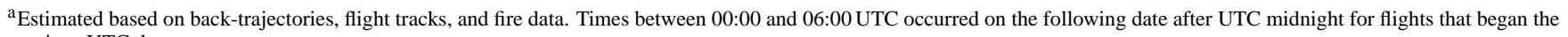
previous UTC day.

${ }^{\mathrm{b}}$ Uncertainty determined from the standard error in the slope of an orthogonal distance regression to a plot of $\mathrm{CO}_{\mathrm{vs}} \mathrm{CO}_{2}$ using data from the 1-s merge. 
should only refer to fresh emissions, whereas an enhancement ratio, also referred to as a normalized excess mixing ratio (NEMR), can refer to the enhancement of a compound $X$ measured downwind from a fire with respect to the enhancement of a smoke tracer $Y$, also reported as $\Delta[X] / \Delta[Y]$. For shorter-lived NMOCs such as ethene and toluene, NEMRs observed downwind of a fire may be significantly lower than the ERs at the source. NMOCs that are oxidation products of compounds emitted during BB may exhibit higher NEMRs downwind of the fire, due to oxidative processing within the plume. Comparisons of NEMRs of these compounds to those of longer-lived primary emissions such as benzene have been used to approximate plume age, based on relative reaction rates (de Gouw et al., 2006). In this work, the term normalized excess mixing ratio (NEMR) is used as many of the plume observations occur far from the fire sources.

Individual NEMRs with respect to $\mathrm{CO}$ were determined for each BB plume in Table 1 for a number of NMOCs measured on board the DC-8 during ARCTAS. For each NMOC $X$ measured during the time period(s) for each plume, $\Delta[X] / \Delta[\mathrm{CO}]$ was determined from the linear leastsquares fit to a plot of $[X]$ (pptv) against $[\mathrm{CO}]$ in ppbv. $\mathrm{CO}$ mixing ratios corresponding to each reported measurement in the TOGA merge were used to determine NEMRs from the TOGA observations. Likewise, the $\mathrm{CO}$ mixing ratios in the WAS merge were used to determine NEMRs for the WAS observations, and the $\mathrm{CO}$ mixing ratios in the 1-minute merge corresponding to each 1-min average PTR-MS, formaldehyde and HCN measurement were used to determine NEMRs for species of interest from those observations. NEMRs are not reported for correlation plots of $[X]$ to [CO] with $r^{2}<0.5$ or where NMOC measurements were not available during the time period(s) specified for a particular plume. For correlations of NMOCs to CO with $r^{2}>0.5$, NEMRs are listed in Table 2 with $1 \sigma$ standard errors from the uncertainties in the slopes. Because some plumes had MCEs greater than unity, which were thus not reported, there is a possibility that strong dilution with a different air mass affected both the MCE and the calculated $\Delta[X] / \Delta[\mathrm{CO}]$. However, by eliminating NEMRs with $r^{2}<0.5$, and reporting uncertainties based on the linear fits to the data, we have confidence in our reported NEMRs and uncertainties.

Relative to the other plumes in Tables 1 and 2, plume 28 contained significantly higher alkane to CO NEMRs, as well as above-average NEMRs for MVK, MACR, acetone, methanol and ethanol. Although the air mass sampled during this time had elevated $\mathrm{BB}$ tracers (i.e. $\mathrm{CO}, \mathrm{HCN}$ and $\mathrm{CH}_{3} \mathrm{CN}$ ), the magnitude of each fire tracer was small in comparison to other fresh plumes sampled during ARCTAS. The MCE of plume $28,1.01 \pm 0.01$, is very different than the mean of the other fresh $(<0.5$ days old $)$ Canadian BB plumes sampled, $0.86 \pm 0.05$. Even if the uncertainty of the MCE for plume 28 is underestimated, an MCE of 0.99 would imply that this must be a $\mathrm{BB}$ plume from a fire in a pure flaming stage in which emission ratios to $\mathrm{CO}$ are high due to overall low $\mathrm{CO}$ emissions. However, it is possible that emissions from non-BB sources were impacting the air mass. This region of central Canada is well known for oil and natural gas extraction (Simpson et al., 2010), and a high proportion of $\mathrm{C}_{2}-\mathrm{C}_{4}$ alkanes in comparison to unsaturated $\mathrm{C}_{2}-\mathrm{C}_{4}$ $\mathrm{NMHC}$ is indicative of natural gas extraction (Katzenstein et al., 2003). Figure 6 is a plot of the average mixing ratios of selected $\mathrm{C}_{2}-\mathrm{C}_{6}$ NMHC (using only WAS observations, for internal consistency) in four different fresh Canadian BB plumes including plume 28. The plot clearly shows that plume 28 has very different ratios of saturated to unsaturated NMHC. Thus, plume 28 is included in Tables 1 and 2 because of its interesting nature, but is omitted from the following discussions and analyses due to the possible non-BB contributions.

To investigate the influences of plume aging and $\mathrm{BB}$ source region, for individual or summed NMOC species, in Fig. 7 the measured NEMRs from the remaining $39 \mathrm{BB}$ plumes are plotted against the estimated average plume age. In these plots, each data point is colored by the primary $\mathrm{BB}$ source region: Alaska, Asia (Spring), Asia (Summer), California or Canada. For mixed sources, the region closest to the sampling is assumed to be the primary BB source region. Yukon and Saskatchewan sources were combined as Canadian BB, and all Asian and Siberian BB were combined as Asian BB, but separated into spring and summer data. The mean NEMRs to $\mathrm{CO}$ for $\mathrm{HCN}, \mathrm{CH}_{3} \mathrm{CN}$ and several oxygenated NMOCs from each of the three major BB source regions measured during ARCTAS (i.e. Asia, California and Canada) are summarized in Table 3, along with selected literature NEMRs from several previous field studies. Likewise, a summary of the mean NEMRs to CO for several NMHC is presented in Table 4 with literature values for comparison. The references listed in Tables 3 and 4 are not intended to be a complete literature survey, but rather are a selection in which several of the same NMOC compounds as those observed during ARCTAS were reported, and are therefore useful for comparison.

\subsection{1 $\mathrm{HCN}$}

The mean HCN to CO NEMR observed during ARCTAS is $7.1 \pm 3.8 \mathrm{pptv} \mathrm{ppbv}^{-1}$ (1 $\sigma$ standard deviation), with an order of magnitude of variability, ranging from $1.56 \pm 0.09$ to $15.1 \pm 1.0 \mathrm{pptv}^{\mathrm{ppbv}}{ }^{-1}$. CO and HCN have tropospheric lifetimes of approximately two months (Fisher et al., 2010) and a few months, respectively, with BB as the primary source and ocean uptake as the primary sink of HCN (Li et al., 2000). In contrast, the primary sink for $\mathrm{CO}$ is reaction with the $\mathrm{OH}$ radical. The ratio of $\mathrm{HCN}$ to $\mathrm{CO}$ in a $\mathrm{BB}$ plume would therefore be relatively unchanged over the first 10 days after emissions, provided there is little dilution with air masses having different $\mathrm{HCN}$ to $\mathrm{CO}$ ratios yet significant amounts of one or the other (e.g. a concentrated urban plume). As shown in Fig. 7 the range of HCN NEMRs observed during ARCTAS is not 


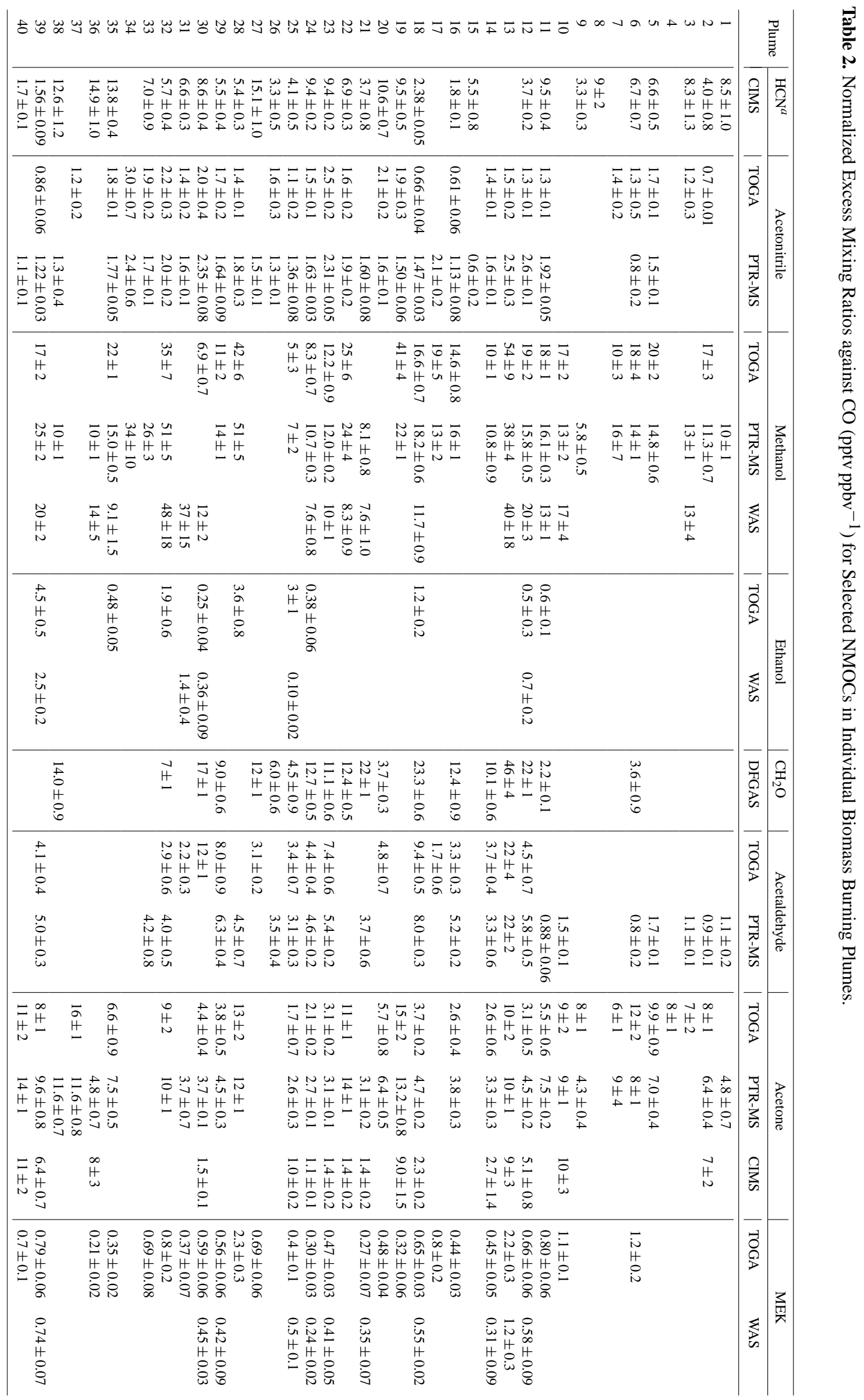




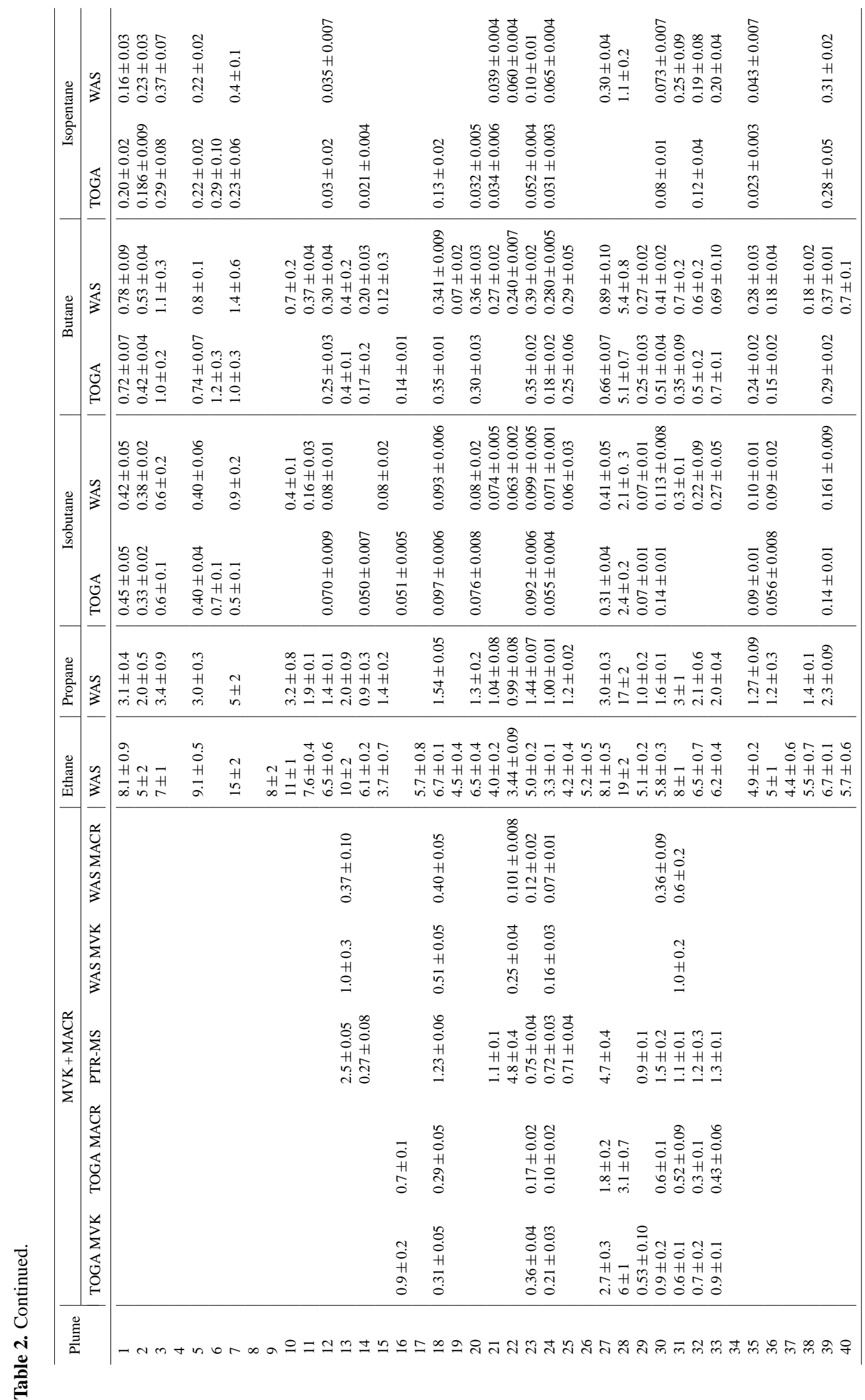




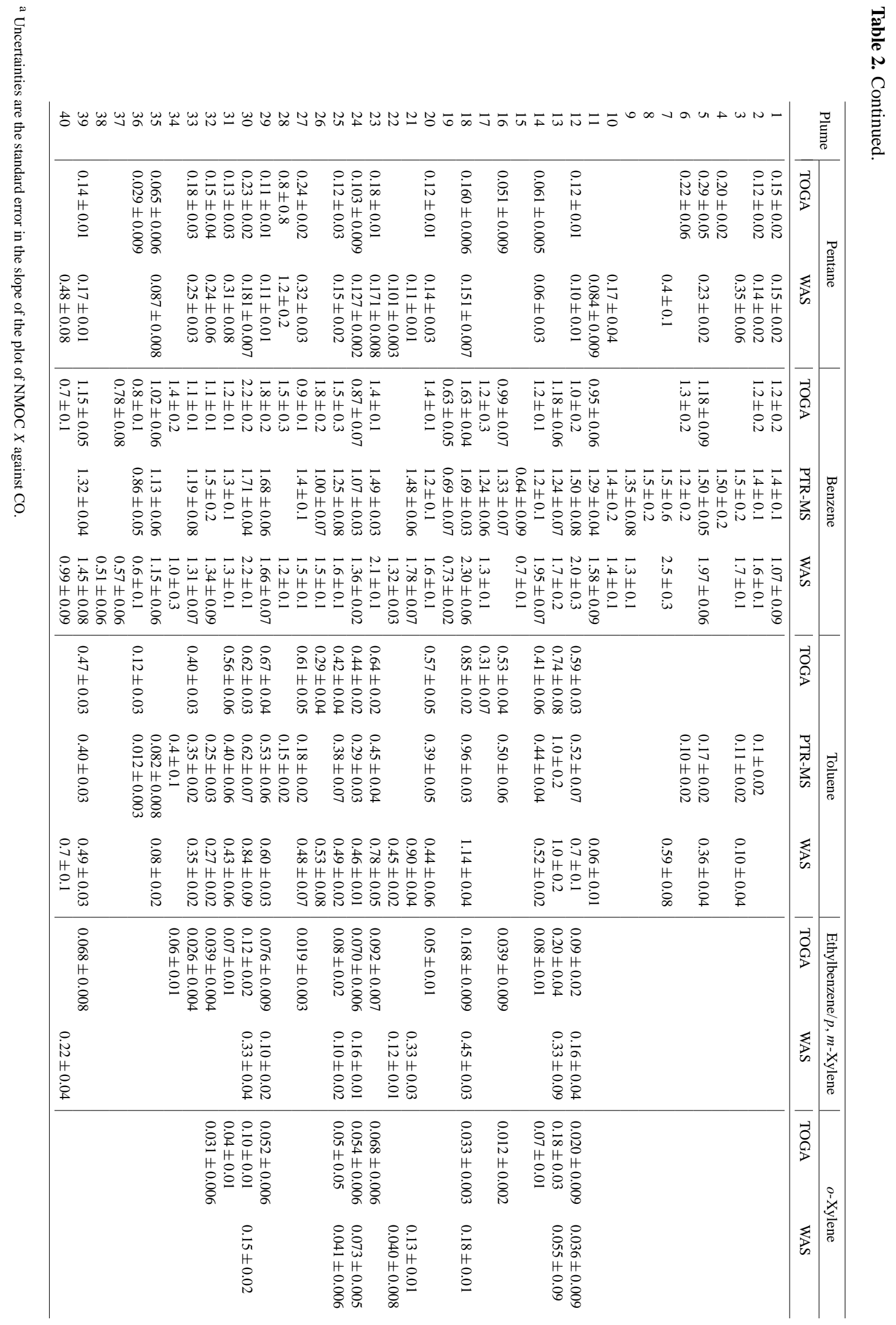




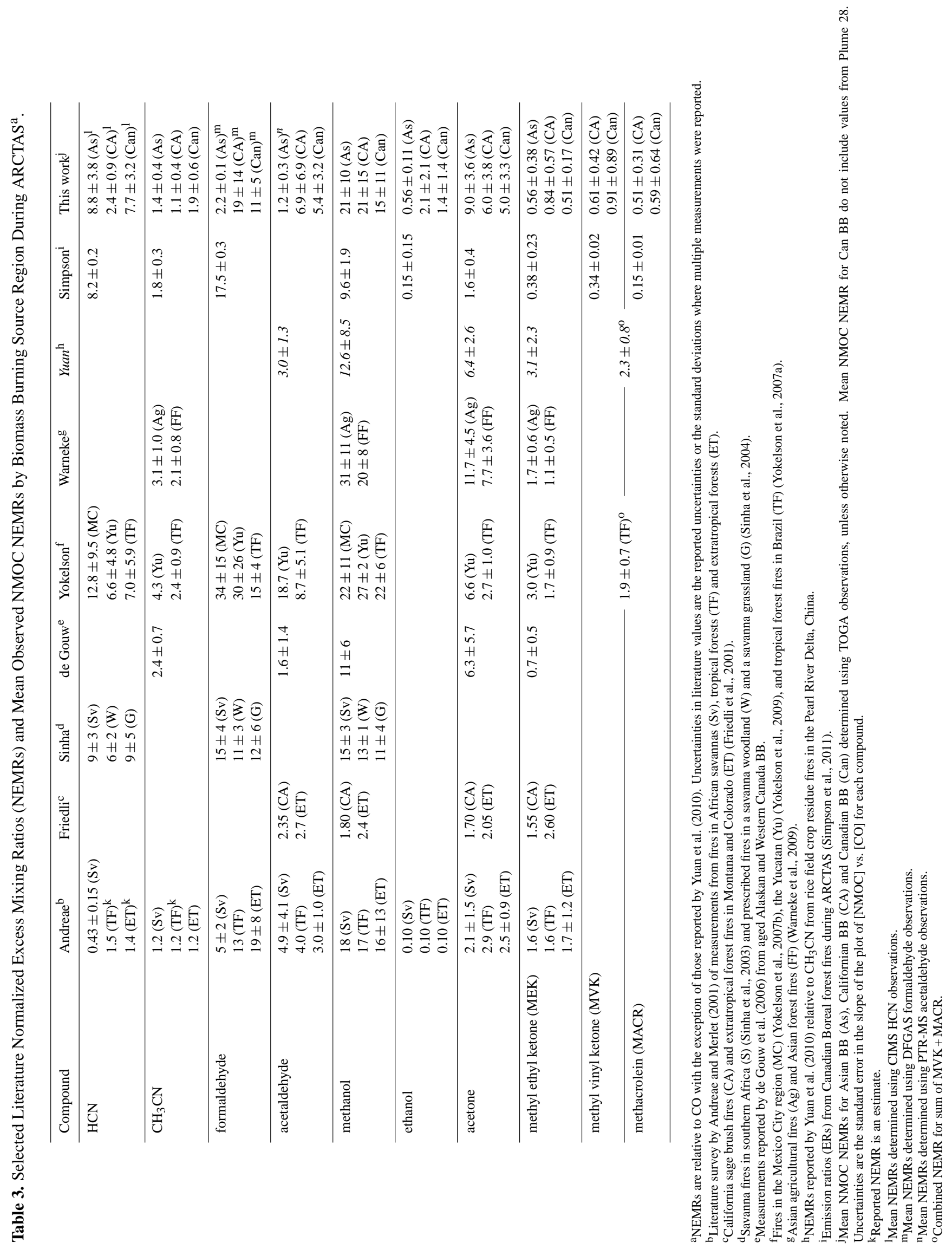




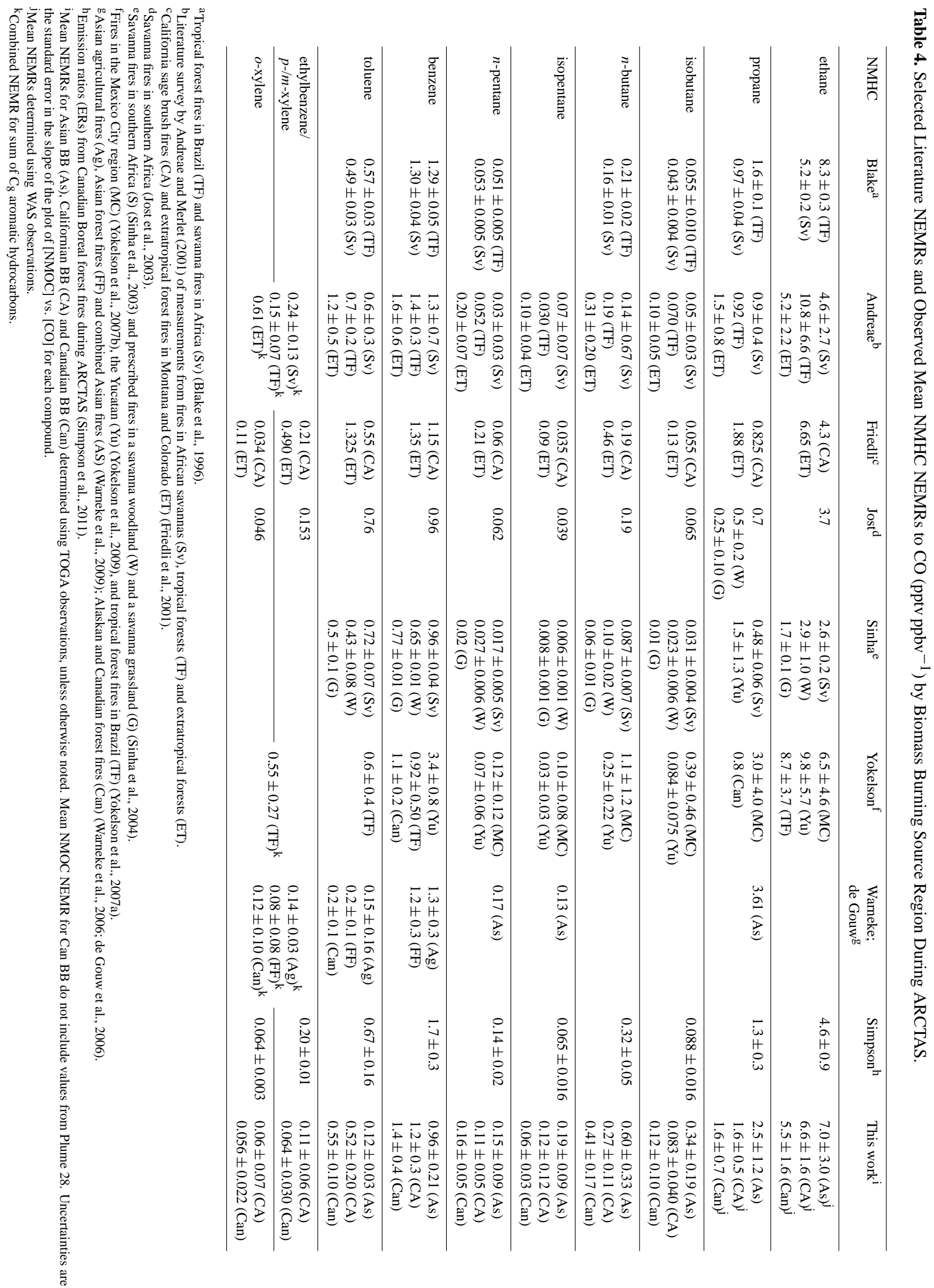




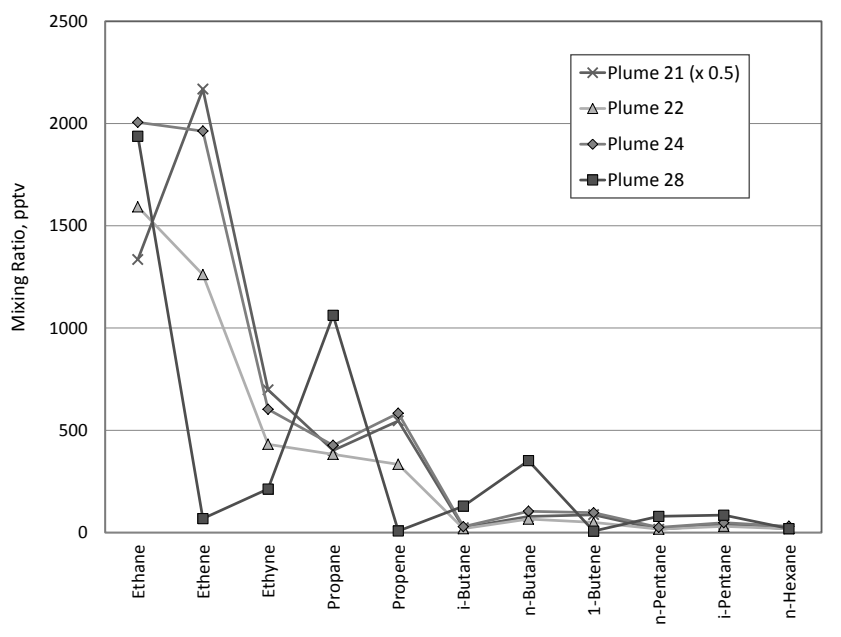

Fig. 6. Average hydrocarbon mixing ratios observed in four different Canadian BB plumes indicating differences in relative proportions of saturated and unsaturated hydrocarbons.

dependent on the average age of the BB plume. Nevertheless, the scatter in the measurements indicates that there is significant variability in $\mathrm{HCN}$ to $\mathrm{CO}$ molar emission ratios.

Observed HCN NEMRs from California fires during ARCTAS-CARB were significantly lower than those from Canadian or Asian fires during spring and summer 2008. The mean HCN to CO NEMRs from the Asian BB, Californian BB and Canadian BB are $8.8 \pm 3.8,2.4 \pm 0.9$ and $7.7 \pm 3.2$ pptv ppbv $^{-1}$, respectively. From Table 3, previous measurements of HCN NEMRs to CO also vary widely. Andreae and Merlet (2001) reported literature averages for three primary BB source regions: African savanna, tropical forest and extratropical forests: $0.43,1.5$ and $1.4 \mathrm{pptv} \mathrm{ppbv}^{-1}$, respectively. NEMRs measured by Sinha et al. $(2003,2004)$ in African savannas were much higher, with average values between 6 and 9 pptv ppbv $^{-1}$. Similarly, Yokelson et al. (2007a, 2009) reported HCN to CO NEMRs from two tropical forest regions in the Yucatan and Brazil averaging between 6.6 and 7.0, but with high variability. As well, Yokelson et al. (2007b) reported HCN NEMRs in the Mexico City region of $12 \pm 7 \mathrm{pptv} \mathrm{ppbv}^{-1}$. This high average $\mathrm{HCN}$ to CO NEMR was attributed to high $\mathrm{NO}_{\mathrm{x}}$ deposition in the mountains surrounding Mexico City and the authors suggested that there may be similarly high ratios near the Los Angeles (LA) Basin. However, the HCN NEMRs measured in California were on average the smallest values observed during the ARCTAS study, and are much lower than the average NEMR from the Mexico City region. It should be noted that most of the wildfires in California during June 2008 were north of the Los Angeles region, primarily in the northern region of California's Central Valley (Fig. 5b), which is likely less impacted by $\mathrm{LA} \mathrm{NO}_{\mathrm{x}}$ pollution than the mountains immediately surrounding the LA Basin. Further, although HCN emissions from motor vehicles are not believed to be important on a global scale, on local and regional scales the impact of anthropogenic emissions of HCN may be significant, as shown for the Mexico City region (Crounse et al., 2009). However, vehicular emissions of HCN depend highly on the average age and catalytic capability of the fleet (Harvey et al., 1983; Baum et al., 2007), which results in a relatively low impact from vehicles in California compared to Mexico City.

The Asian and Canadian fires were primarily in boreal forests, whereas the Californian fires involved a number of different fuels, including grass and shrubs, as well as mixed coniferous forests. The differences in the measured HCN NEMRs could be indicative of the different fuels and fire conditions in Asia and Canada compared to those in California.

\subsubsection{Acetonitrile}

As shown in Table 3, reported NEMRs for $\Delta\left[\mathrm{CH}_{3} \mathrm{CN}\right] / \Delta[\mathrm{CO}]$ typically range between 1.2 and 4.3 pptv ppbv ${ }^{-1}$. The mean $\mathrm{CH}_{3} \mathrm{CN}$ to $\mathrm{CO}$ NEMR observed during ARTCAS is $1.5 \pm 0.6 \mathrm{pptv}_{\mathrm{ppbv}}{ }^{-1}$ using the TOGA $\mathrm{CH}_{3} \mathrm{CN}$ data, and $1.7 \pm 0.6 \mathrm{pptv}_{\mathrm{ppbv}}{ }^{-1}$ using the PTR-MS data, both within the range of previously reported values but certainly on the low end. Separating the data by source region, the mean observed NEMRs from the Asian, Californian and Canadian BB are $1.4 \pm 0.4,1.1 \pm 0.4$ and $1.9 \pm 0.6$ (all pptvppbv ${ }^{-1}$ ), respectively, using the TOGA $\mathrm{CH}_{3} \mathrm{CN}$ measurements, and $1.4 \pm 0.5,1.7 \pm 0.6$, and $1.8 \pm 0.4\left(\right.$ pptv ppbv $\left.^{-1}\right)$ using the PTR-MS $\mathrm{CH}_{3} \mathrm{CN}$ data. Unlike HCN, the observations from ARCTAS suggest that $\mathrm{CH}_{3} \mathrm{CN}$ to $\mathrm{CO}$ emission ratios do not vary significantly between the BB source regions sampled, making $\mathrm{CH}_{3} \mathrm{CN}$ a particularly good biomass burning tracer. Additionally, both the overall mean NEMR and the regional mean NEMRs are statistically equivalent using $\mathrm{CH}_{3} \mathrm{CN}$ data from either the TOGA or PTR-MS. For the remainder of the NMOC NEMRs discussed in Sect. 3.3, unless noted due to significant differences between the measurements, we refer to NEMRs determined using the TOGA data for compounds for which TOGA measurements exist.

\subsubsection{Oxygenated NMOCs}

Observed formaldehyde to CO NEMRs ranged between $2.2 \pm 0.1$ and $46 \pm 4 \mathrm{pptv} \mathrm{ppbv}^{-1}$ during ARCTAS, with an overall mean of $13 \pm 10 \mathrm{pptv} p p b v^{-1}$. Regionally, the means for Asian, Californian and Canadian BB are 2.2 \pm 0.1 , $19 \pm 14$, and $11 \pm 5 \mathrm{pptv} p p b v^{-1}$, respectively. Only one NEMR was observable in the Asian BB within our criteria, but with a relatively short tropospheric lifetime of approximately 1 day, this is not surprising. Literature NEMRs for formaldehyde range between $5 \pm 2 \mathrm{pptv}_{\mathrm{ppbv}}{ }^{-1}$ and $34 \pm 15$ pptv ppbv $^{-1}$ (Table 3 ).

The acetaldehyde to CO NEMRs observed during ARCTAS range from as high as $22 \mathrm{pptv}_{\mathrm{ppbv}}{ }^{-1}$, measured by both 


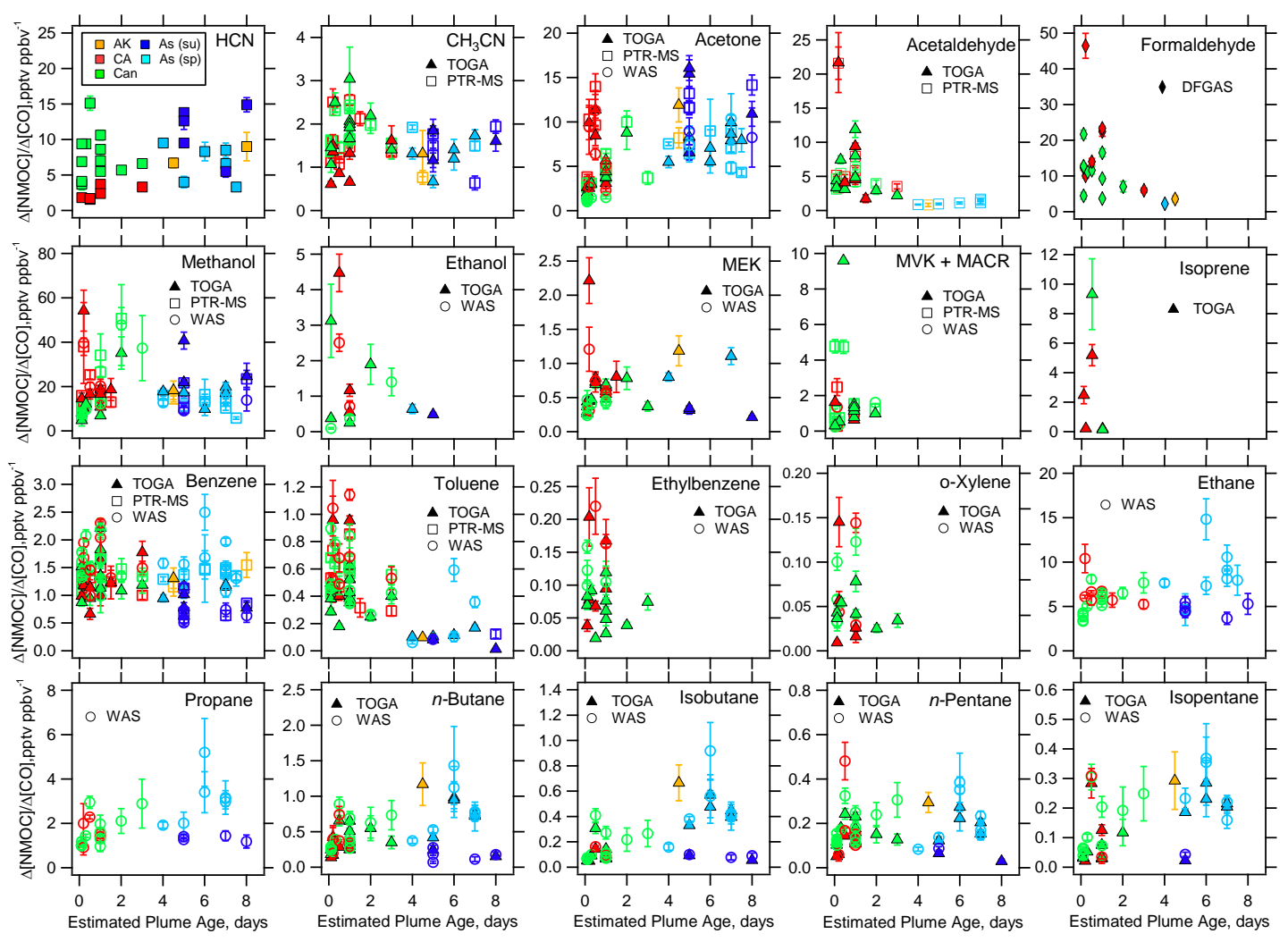

Fig. 7. Plots of observed NEMRs for several NMOCs to CO from individual BB plumes observed during ARCTAS against estimated plume age. Error bars show the standard error in the slope of a linear fit to [NMOC] vs. [CO] for each BB plume. Points are colored by the BB source region and, for Asian BB, time of year (spring or summer), as shown in the legend on the HCN plot.

TOGA and PTR-MS in a fresh BB plume over California, to less than 2 pptv ppbv $^{-1}$ in several long-range Asian BB plumes measured by the PTR-MS during the spring campaign. For shorter-lived NMOCs, NEMRs are expected to decrease as the plume ages. In the acetaldehyde plot in Fig. 7 there is a decrease in the observed NEMRs with estimated $\mathrm{BB}$ plume age. Although a number of Asian BB plumes were sampled during both the spring and summer campaigns, of those estimated to be more than four days old only a few of the spring BB plumes contained sufficient acetaldehyde to determine the NEMR, averaging $1.2 \pm 0.3 \mathrm{pptv} \mathrm{ppbv}^{-1}$ (using the PTR-MS data). Mean acetaldehyde to CO NEMRs from younger Californian and Canadian BB were $6.9 \pm 6.9$ and $5.4 \pm 3.2 \mathrm{pptv} \mathrm{ppbv}^{-1}$, respectively, with a clear dependence on the age of the BB plume. Acetaldehyde has a tropospheric lifetime of approximately 1 day with the primary loss due to reaction with $\mathrm{OH}$. Thus, the increased average $[\mathrm{OH}]$ in summer months at mid- to high-latitudes is the most likely reason long-range acetaldehyde NEMRs were not observed in the summer, rather than a difference in emission ratios between the spring and summer fires. Observable differences between the spring and summer NEMRs in Asian BB were seen for a number of other NMOCs, including MEK, benzene, and the $\mathrm{C}_{2}-\mathrm{C}_{5}$ alkanes, and are likely also due to in- creased $\mathrm{OH}$ loss rates of these NMOCs during the summer months.

Literature observations of acetaldehyde NEMRs and emission ratios also vary widely. Yokelson et al. (2007a) reported acetaldehyde NEMRs to CO of $8.7 \pm 5.1 \mathrm{pptv} \mathrm{ppbv}^{-1}$ from deforestation fires in Brazil and $18.7 \mathrm{pptv}_{\mathrm{ppbv}}{ }^{-1}$ from fresh fire emissions in the Yucatan (Yokelson et al., 2009), while de Gouw et al. (2006) reported acetaldehyde NEMRs well below 2 pptv ppbv ${ }^{-1}$ in aged Alaskan and western Canada BB plumes sampled over the northeastern United States. In the latter, the relative ratios of acetaldehyde and benzene NEMRs to CO indicated secondary production of acetaldehyde within the BB plumes.

Using data from five of the very young BB plumes sampled (plumes 13, 14, 23-25), we determined an emission factor (EF) for acetaldehyde from the Californian and Canadian $\mathrm{BB}$ of $1.8 \pm 1.3 \mathrm{~g} \mathrm{~kg}^{-1}$. An EF is defined as the mass in grams of compound $X$ emitted per kilogram of fuel burned, and can be determined as described by Yokelson et al. (1999) using

$\mathrm{EF}_{X}\left(\frac{\mathrm{g}}{\mathrm{kg}}\right)=\mathrm{F}_{\mathrm{C}} \cdot \frac{\mathrm{MM}_{X}}{\mathrm{MM}_{\mathrm{C}}} \cdot \frac{\mathrm{C}_{X}}{\mathrm{C}_{\mathrm{T}}}$ 
Here $\mathrm{F}_{\mathrm{C}}$ is the mass fraction of carbon in the fuel (assumed to be $500 \mathrm{gC} \mathrm{kg}^{-1}$; Susott et al., 1996), $\mathrm{MM}_{X}$ and $\mathrm{MM}_{\mathrm{C}}$ are the molecular masses of $X$ and carbon $\left(12.011 \mathrm{~g} \mathrm{~mol}^{-1}\right)$, respectively, and $\mathrm{C}_{X} / \mathrm{C}_{\mathrm{T}}$ is the ratio of the number of emitted moles of $X$ to the emitted moles of carbon. Simpson et al. (2011) reported EFs for the majority of NMOC observed in fresh Canadian BB plumes during ARCTAS, but not for acetaldehyde and thus we include it here. The acetaldehyde EF for ARCTAS is consistent with values compiled by Akagi et al. (2011) for BB emissions from peatland $\left(2.81 \pm 1.36 \mathrm{~g} \mathrm{~kg}^{-1}\right)$ and tropical forest fires $\left(1.55 \pm 0.75 \mathrm{~g} \mathrm{~kg}^{-1}\right)$, and provides an value for acetaldehyde emissions from boreal forest fires, previously not available.

The methanol NEMRs to $\mathrm{CO}$ observed during ARCTAS range between 5 and $54 \mathrm{pptv} p p b v^{-1}$, with a mean of $19 \pm 12 \mathrm{pptv} p p b v^{-1}$. By source region, the mean methanol NEMRs of $21 \pm 10,21 \pm 15$ and $15 \pm 11$, all pptv ppbv ${ }^{-1}$, in Asian, Californian and Canadian BB plumes, respectively, indicate very little difference between source region and plume age. Unlike acetone, little photochemical production of methanol is expected. Published NEMRs of methanol to $\mathrm{CO}$ also cover a wide range, between 1.8 (Friedli et al., 2001) and $27 \pm 10.2$ pptv ppbv $^{-1}$ (Yokelson et al., 2009), yet the majority lie between 10 and $25 \mathrm{pptv}_{\mathrm{ppbv}}{ }^{-1}$.

TOGA ethanol NEMRs to CO ranging from $0.25 \pm 0.04$ to $4.5 \pm 0.5 \mathrm{pptv}_{\mathrm{ppbv}}{ }^{-1}$ with a mean of $1.4 \pm 1.4 \mathrm{pptv} \mathrm{ppbv}^{-1}$ were observed during ARCTAS, primarily in fresh Canadian and Californian BB plumes. The majority of the corresponding TOGA- and WAS-determined NEMRs in this work agree to within $50 \%$ (Table 2), with the only major difference seen in plume 25 , a very brief interception of fresh Canadian BB. Using the same plume selection criteria, the WAS ethanol NEMRs ranged between $0.10 \pm 0.02$ and $2.5 \pm 0.2 \mathrm{pptv} \mathrm{ppbv}^{-1}$, with a campaign mean NEMR of $1.0 \pm 1.0 \mathrm{pptv}^{\mathrm{ppbv}}{ }^{-1}$, including a Canadian BB mean NEMR of $0.62 \pm 0.69 \mathrm{pptv} p p b v^{-1}$. The corresponding TOGA mean NEMR for the Canadian BB is $1.0 \pm 1.1 \mathrm{pptv}^{\mathrm{ppbv}}{ }^{-1}$. To the authors' knowledge, the only published ethanol BB data include three EFs: $0.002 \pm 0.002$ and $0.051 \pm 0.139 \mathrm{~g} \mathrm{~kg}^{-1}$ (Ciccioli et al., 2001), obtained in laboratory experiments with two different fuels in both flaming and smoldering stages, and $0.018 \mathrm{~g} \mathrm{~kg}^{-1}$ corresponding to a molar emission ratio to $\mathrm{CO}$ of $0.10 \mathrm{pptv}_{\mathrm{ppbv}}^{-1}$ (Andreae and Merlet, 2001), as well as an ER of $0.15 \pm 0.15 \mathrm{pptv}^{\mathrm{ppbv}}{ }^{-1}$ (Simpson et al., 2011). The ER from Simpson et al. was determined using WAS observations from Canadian fires during ARCTAS, but with different BB plume selection criteria and averaging than in this work. Overall, the smallest ethanol NEMR reported here is in agreement with published values, but the NEMRs in Table 2 indicate that $\mathrm{BB}$ emission ratios of ethanol to $\mathrm{CO}$ can range up to an order of magnitude larger than previous measurements suggest. From plumes 24 and 25, the freshest BB plumes with observable ethanol NEMRs, we determined an EF for ethanol from boreal forest fire emissions of
$0.57 \pm 0.62 \mathrm{~g} \mathrm{~kg}^{-1}$, which is an order of magnitude greater than the previous-reported EFs. Thus, emission inventories based on previously-published measurements may significantly underestimate the magnitude of fire-emitted ethanol.

The NEMRs of acetone to $\mathrm{CO}$ observed during ARCTAS range from $1.7 \pm 0.7$ to $16 \pm 1 \mathrm{pptv} p p b v^{-1}$, with a mean NEMR of $7.1 \pm 3.9 \mathrm{pptv}^{\mathrm{ppbv}}{ }^{-1}$. Separated by source region, the mean NEMRs are 9.0 $\pm 3.6,6.0 \pm 3.8$, and $5.0 \pm 3.3$, all pptv ppbv ${ }^{-1}$, in Asian, Californian and Canadian BB, respectively. Jost et al. (2003) reported an increase in acetone NEMRs to $\mathrm{CO}$ in an aging fire plume over a much shorter timescale, ranging from $4.8 \mathrm{pptv} \mathrm{ppbv}^{-1}$ in a fire plume estimated to be $17 \mathrm{~min}$ old to $11.3 \mathrm{pptv}^{\mathrm{ppbv}}{ }^{-1}$ downwind in the same fire plume estimated to be $125 \mathrm{~min}$ old. Other literature values for $\Delta[$ acetone $] / \Delta[C O]$ NEMRs range between $1.5 \mathrm{pptv} \mathrm{ppbv}^{-1}$ (Holzinger et al., 2005) and 1.7-2.1 pptv ppbv ${ }^{-1}$ (Friedli et al., 2001) in very young fire plumes to $19.5 \mathrm{pptv}^{\mathrm{ppbv}}{ }^{-1}$ (Andreae and Merlet, 2001) and 20-30 pptv ppbv ${ }^{-1}$ (Singh et al., 1994) in aged biomass burning plumes. Larger acetone to CO NEMRs were observed in Asian BB plumes during the summer campaign than in the spring, which is also consistent with higher photochemical processing in the summertime.

The MEK NEMRs observed during ARCTAS range between 0.21 and $2.2 \mathrm{pptvppbv}^{-1}$ with a mean of $0.65 \pm 0.41 \mathrm{pptv}^{\mathrm{ppbv}}{ }^{-1}$, similar to published MEK NEMRs to $\mathrm{CO}$ which range between 0.7 and $3.0 \mathrm{pptv} \mathrm{ppbv}^{-1}$ (Table 3). Separated by source region, the respective mean MEK NEMRs from Asian, Californian and Canadian BB of $0.56 \pm 0.38,0.84 \pm 0.57$ and $0.51 \pm 0.17 \mathrm{pptv} p p b v^{-1}$, are statistically equivalent, with no clear dependence on BB plume age or source region. There is, however, a statistical difference between the spring and summer Asian BB NEMRs: $1.0 \pm 0.2$ and $0.29 \pm 0.07 \mathrm{pptv} \mathrm{ppbv}^{-1}$, respectively. The MEK OH rate coefficient is approximately $1.22 \times 10^{-12} \mathrm{~cm}^{3}$ molecule ${ }^{-1} \mathrm{~s}^{-1}$ (Atkinson and Arey, 2003) and the photolytic lifetime is estimated to be on the same order of magnitude as OH-removal (Raber and Moortgat, 1995; Atkinson, 2000). Thus, the difference in the MEK tropospheric lifetime between the spring and summer months is the likely reason for the difference in the observed NEMRs, although it is also conceivable that the differences are due to differences in the emissions from the Asian fires burning in the spring and summer.

The MVK to CO NEMRs observed during ARCTAS range between 0.2 and $2.7 \mathrm{pptv} p p b v^{-1}$, with mean NEMRs of $0.61 \pm 0.42$ and $0.91 \pm 0.89$ pptv ppbv $^{-1}$ from Californian and Canadian BB, respectively. The observed methacrolein NEMRs to CO range between 0.10 and $1.8 \mathrm{pptv} p p b v^{-1}$, with respective mean NEMRs to $\mathrm{CO}$ of $0.51 \pm 0.31$ and $0.59 \pm 0.64$ pptv ppbv $^{-1}$ from Californian and Canadian BB. Few NEMRs for these isoprene oxidation products have been published. Yokelson et al. (2007a) reported an NEMR to CO for the sum of MVK + MACR of $1.9 \pm 0.7 \mathrm{pptv} \mathrm{ppbv}^{-1}$ from Brazilian deforestation fires. Recently, Yuan et al. (2010) 
reported an NEMR for the sum of MVK + MACR to $\mathrm{CH}_{3} \mathrm{CN}$ of $2.3 \pm 0.8\left(\right.$ pptv pptv $^{-1}$ ) in the Pearl River Delta (PRD) region of China. Applying our mean NEMR for $\mathrm{CH}_{3} \mathrm{CN}$ to $\mathrm{CO}$ of $1.5 \pm 0.6 \mathrm{pptv}_{\mathrm{ppbv}}{ }^{-1}$, we estimate the PRD NEMR to $\mathrm{CO}$ at $3.5 \pm 1.8 \mathrm{pptv}_{\mathrm{ppbv}}{ }^{-1}$. Combined, the MVK + MACR NEMRs from fresh Californian and Canadian BB range between $0.31 \pm 0.05$ and $4.5 \pm 0.4 \mathrm{pptv}_{\mathrm{ppbv}}{ }^{-1}$, with a mean value of $1.3 \pm 1.2 \mathrm{pptv}_{\mathrm{ppbv}}^{-1}$, in agreement with the few published values. Using the WAS ARCTAS data from fires in Canada, Simpson et al. (2011) reported MVK and MACR ERs to CO of $0.34 \pm 0.02$ and $0.15 \pm 0.01$, both pptv ppbv ${ }^{-1}$, respectively. Using only the very young Canadian BB plumes, (plumes 21-25), the mean MVK and MACR NEMRs determined using the TOGA data are $0.29 \pm 0.11 \mathrm{pptv}_{\mathrm{ppbv}}{ }^{-1}$ and $0.1 \pm 0.1 \mathrm{pptv}_{\mathrm{ppbv}}{ }^{-1}$, respectively, in better agreement with the ERs reported by Simpson and co-authors. This is consistent with the ratios of these isoprene oxidation products to $\mathrm{CO}$ being initially quite low in boreal forest fire emissions, then increasing in concentration with respect to $\mathrm{CO}$ as isoprene in the plume is oxidized. However, with tropospheric lifetimes $<1$ day, MVK and MACR enhancements to $\mathrm{CO}$ are not expected to remain elevated, which is consistent with the observations: no MVK or MACR NEMRs could be determined in plumes older than 2 days.

In addition to MVK and MACR, isoprene was observed in several BB plumes, with NEMRs to $\mathrm{CO}$ ranging from $0.14 \pm 0.07$ to $5.2 \pm 0.7 \mathrm{pptv}_{\mathrm{ppbv}}{ }^{-1}$. Isoprene enhancement ratios have been previously reported, but because the tropospheric lifetime of isoprene is so short (i.e. a few hours or less) it is difficult to extract meaning from enhancement ratio observations. It is also not possible to determine from the observed enhancements in the ARCTAS BB plumes the relative contributions of natural isoprene emissions and biomass burning emissions. Regardless of the origin of the emissions, because of the very short atmospheric lifetime of isoprene, in the absence of deep convection, mixing ratios of isoprene in the upper troposphere are very low. During ARCTAS, there were several occasions during which significant isoprene mixing ratios were observed above $8 \mathrm{~km}$, most likely as a result of strong convection over Canada where biogenic emissions are high and BB occurs. These convective events and the impact of reactive isoprene on the $\mathrm{HO}_{\mathrm{x}}$ budget of the upper troposphere are explored in another paper (Apel et al., 2011).

\subsubsection{Alkanes}

The ethane to CO NEMRs observed during ARCTAS range between $3.3 \pm 0.1$ and $15 \pm 2 \mathrm{pptv}_{\mathrm{ppbv}}{ }^{-1}$, with a mean value of $6.3 \pm 2.3 \mathrm{pptv}_{\mathrm{ppbv}}^{-1}$, similar to published values (Table 4) which range between $1.7 \pm 0.1 \mathrm{pptv}_{\mathrm{ppbv}}{ }^{-1}$ from fires in savanna grasslands (Sinha et al., 2004) and $10.8 \pm 6.6 \mathrm{pptv} \mathrm{ppv}^{-1}$ from tropical forest fires (Andreae and Merlet, 2001). Overall, the mean ethane NEMR from Asian BB, including data from ARCTAS-A, -CARB and $-B$, is $7.0 \pm 3.0 \mathrm{pptv} p p b v^{-1}$, and the mean ethane NEMRs from Californian and Canadian BB are $6.6 \pm 1.6$ and $5.5 \pm 1.6 \mathrm{pptv}_{\mathrm{ppbv}}{ }^{-1}$, respectively. As with MEK, there is an observed difference between the mean ethane NEMRs observed in Asian BB plumes during the spring and summer campaigns, $8.8 \pm 3.0$ and $4.7 \pm 0.7 \mathrm{pptv}_{\mathrm{ppbv}}{ }^{-1}$, respectively. Using the same WAS data set, but with different plume selection and averaging, Simpson et al. (2011) reported an ethane to CO ER for Canadian BB during ARCTAS of $4.6 \pm 0.9 \mathrm{pptv} p p b v^{-1}$, consistent with the mean ethane NEMR determined in this work. Simpson and co-authors also reported an ethane to CO ER from a Siberian boreal forest fire plume interception on 29 June $\left(4.63 \pm 0.08 \mathrm{pptv}_{\mathrm{ppbv}}{ }^{-1}\right.$, corresponding to plume 19 in this work: $\left.4.5 \pm 0.5 \mathrm{pptv} \mathrm{ppbv}^{-1}\right)$, which combined with findings from a previous study (ABLE-3B, Blake et al., 1994) led the authors to conclude that there may be a characteristic boreal forest fire emission signature. However, our plume 7 was also traced to the Siberian boreal forest region and has an ethane to CO NEMR of $15 \pm 2$ pptv ppbv ${ }^{-1}$. In terms of the range of NEMRs observed, we observed no difference between the boreal forest fires from Siberia and the agricultural fires from East Asia/Kazakhstan. Likewise there was no statistical difference between the Californian and Canadian fires and the Asian fires.

The propane NEMRs observed during ARCTAS vary between $0.9 \pm 0.3$ and $5 \pm 2 \mathrm{pptv} p p b v^{-1}$, with a mean of $2.0 \pm 1.0 \mathrm{pptv} p p b v^{-1}$. There is statistically no difference between the mean NEMRs from Asian, Californian and Canadian BB sources, $2.5 \pm 1.2,1.6 \pm 0.5$ and $1.6 \pm 0.7 \mathrm{pptv}_{\mathrm{ppbv}}{ }^{-1}$, respectively, although the Asian mean is nominally larger than the two North American means. Separating the Asian NEMRs into spring and summer means, $3.1 \pm 1.1$ and $1.3 \pm 0.1 \mathrm{pptv} \mathrm{ppbv}^{-1}$, respectively, suggests differences in $\mathrm{OH}$-removal rates and shows that the summertime values from all three locations are indeed similar. The difference between the spring and summer means is also consistent with the larger observed acetone NEMRs in the summer compared to the spring observations, as acetone is a major product of propane oxidation. The observed propane to CO NEMRs are in agreement with the published values in Table 4, which range from $0.25 \pm 0.10$ (Sinha et al., 2004) to $3.0 \pm 4.0 \mathrm{pptv}_{\mathrm{ppbv}}^{-1}$ (Yokelson et al., 2007b).

Published isobutane to CO NEMRs range between 0.01 from savanna grassland fires (Sinha et al., 2004) and $0.39 \pm 0.46 \mathrm{pptv} \mathrm{ppbv}^{-1}$ from fires in the regions around Mexico City (Yokelson et al., 2007b). The relative enhancements observed during ARCTAS are all within the range of previously reported values, with a mean of $0.22 \pm 0.20 \mathrm{pptv}_{\mathrm{ppbv}}{ }^{-1}$. Likewise, published $n$-butane to CO NEMRs range between $0.06 \pm 0.01$ (Sinha et al., 2004) and $1.1 \pm 1.2$ (Yokelson et al., 2007b), both pptvppbv ${ }^{-1}$. The NEMRs observed during ARCTAS fall within this range, with an overall mean NEMR of 
$0.46 \pm 0.29 \mathrm{pptv}_{\mathrm{ppbv}}{ }^{-1}$. As shown in Table 4, the NEMRs for isopentane and $n$-pentane also fall within the range of previously published values.

\subsubsection{Aromatic hydrocarbons}

The observed benzene to CO NEMRs during ARCTAS are quite consistent, regardless of source, and although they range between $0.63 \pm 0.05$ and $2.2 \pm 0.2$ pptv ppbv $^{-1}$, the overall mean is $1.2 \pm 0.4 \mathrm{pptv}_{\mathrm{ppbv}}{ }^{-1}$. By source region, the mean benzene to CO NEMRs are $0.96 \pm 0.21,1.2 \pm 0.3$ and $1.4 \pm 0.4$ pptv ppbv $^{-1}$ for Asian, Californian and Canadian BB, respectively. There is a slight separation between the Asian BB NEMRs observed during the spring and summer: $1.11 \pm 0.11$ and $0.80 \pm 0.16$ pptv ppbv $^{-1}$, respectively. With the exception of the reported average benzene NEMR from observations in smoke plumes in the Yucatan (Yokelson et al., 2009) (3.4 \pm 0.8 pptv ppbv $\left.{ }^{-1}\right)$, the published benzene NEMRs listed in Table 4 are all between $0.65 \pm 0.01$ and $1.6 \pm 0.6 \mathrm{pptv}_{\mathrm{ppbv}}{ }^{-1}$.

The literature values for toluene NEMRs to $\mathrm{CO}$ shown in Table 4 range between 0.18 and $1.3 \mathrm{pptv} p p b v^{-1}$. During ARCTAS, the observed toluene NEMRs ranged between $0.12 \pm 0.03$ and $0.85 \pm 0.02 \mathrm{pptv}^{\mathrm{ppbv}}{ }^{-1}$, with an overall mean of $0.51 \pm 0.18 \mathrm{pptv}^{\mathrm{ppbv}}{ }^{-1}$. As a relatively shortlived species with respect to $\mathrm{CO}, \Delta[$ toluene $] / \Delta[\mathrm{CO}] \mathrm{NEMRs}$ generally decrease with increasing plume age, as shown in Fig. 7, with significant spread in the observed values in young BB plumes. The mean regional NEMRs for Asian, Californian and Canadian BB, $0.12 \pm 0.03,0.51 \pm 0.19$ and

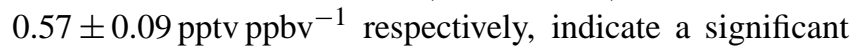
decrease in the Asian BB toluene NEMRs between emission and sampling, and no statistical difference between Canadian and Californian toluene NEMRs.

Published values for $\mathrm{C}_{8}$-aromatics NEMRs with respect to $\mathrm{CO}$ range between $0.15 \pm 0.07 \mathrm{pptv} \mathrm{ppbv}^{-1}$ (Andreae and Merlet, 2001) and $0.55 \pm 0.27 \mathrm{pptv} p p b v^{-1}$ for the combined ethylbenzene $+p-,+m-$, $+o$-xylene (Yokelson et al., 2007a). Having lower mixing ratios than toluene with shorter lifetimes, these NEMRs were only observed in the Californian and Canadian BB. The $\mathrm{C}_{8}$-aromatic NEMRs are on the lower end of the published values, ranging from $0.012 \pm 0.002$ (o-xylene) to $0.20 \pm 0.04$ (ethylbenzene $+p$ - and $m$-xylene) pptv ppbv ${ }^{-1}$, and having a mean of $0.08 \pm 0.05 \mathrm{pptv}_{\mathrm{ppbv}}{ }^{-1}$ for ethylbenzene, $p$ - $+m$-xylene,

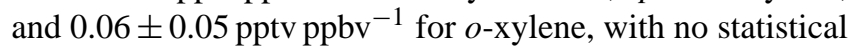
difference between Californian and Canadian BB NEMRs.

\subsection{Ratios of NMOC enhancements}

Figure 8 shows comparison plots of the NEMRs of ethane, $n$-butane, isobutane and $n$-pentane against the co-observed NEMR for propane to CO, using the WAS data for internal consistency. Again, because the NEMRs observed in plume 28 are outliers and may not include only BB emissions, these data are not included in the plots or the linear fits. In general, the ratios to $\mathrm{CO}$ of these light alkanes are not strongly correlated with the estimated photochemical age of the BB plume, though a range of NEMRs were observed for each NMOC during ARCTAS. The black line is a linear fit to the observed ARCTAS data. Also included are the equivalent literature ratios from Table 4 with the text centered on the value.

Figure $8 \mathrm{a}$ is a comparison plot for ethane and propane NEMRs to CO. The fit to the observed ARCTAS data has a slope of $2.1 \pm 0.3$ and an $r^{2}$ value of 0.72 , with only a few of the literature ratios and one of the observed points deviating significantly from the fit. Figure $8 \mathrm{~b}$ is the comparison plots of $n$-butane and propane NEMRs to CO. Similar to the ethane versus propane plot, the linear fit to the observed $n$ butane versus propane NEMRs indicates very good correlation with a slope of $0.29 \pm 0.02$, and an $r^{2}$ value of 0.89 . As well, the majority of the literature values on the plots are well described by the linear fit. The next plot, Fig. 8c, shows the NEMR comparison for isobutane and propane. Again a linear fit to the data indicates very good correlation between isobutane and propane emissions, with a slope of $0.19 \pm 0.01$ and an $r^{2}$ value of 0.92 . The next two plots are comparison plots of $n$-pentane (d) and isopentane (e) NEMRs to the observed propane NEMRs. For the $n$-pentane NEMRs, the linear fit to the ARCTAS data has a slope of $0.068 \pm 0.011$, with an $r^{2}$ value of 0.65 . Likewise, the linear fit for the isopentane versus propane plot has a slope of $0.09 \pm 0.01$ and an $r^{2}$ value of 0.70. Both fits indicate less correlation than in Fig. 8a-c, but this is not surprising considering the smaller observed mixing ratios resulting in higher uncertainties in the correlation plots. Overall, the comparisons shown in Fig. 8 suggest strong correlations between the emissions of light $\mathrm{C}_{2}-$ $\mathrm{C}_{5}$ alkanes from fires. These correlations are reasonable as it is known that similar compounds can be emitted by specific combustion processes, e.g. alkanes are mostly made by glowing combustion (along with $\mathrm{CO}$ ), while oxygenated NMOC are mostly made by pyrolysis (along with $\mathrm{CO}$ ) (Yokelson et al., 1996, 1997). As a result, the ratio of NEMRs for two NMOC of similar structure may be less scattered than the individual species' NEMRs to CO. However, because light alkanes each have different $\mathrm{OH}$ rate constants, the ratios of their NEMRs may provide insight into the plume age. Although this would have little impact on the ratios of ethane to propane (Fig. 8a) over the age of the plumes shown, this may explain the scatter in Fig. 8d-e, in which the ratios of the alkane NEMRs in the older plumes tend to be lower than those of the younger plumes.

Figure 9 shows similar comparisons of the observed and literature NEMRs to $\mathrm{CO}$ for aromatic hydrocarbons to each other and to the propane NEMRs. Figure 9a is a plot of the WAS-observed benzene to CO NEMRs from ARCTAS against propane. A linear fit through the observations indicates very little correlation with an $r^{2}$ value of 0.06 . In Fig. 9b, a comparison plot of the NEMRs to CO for toluene against benzene from all three measurement systems, there 

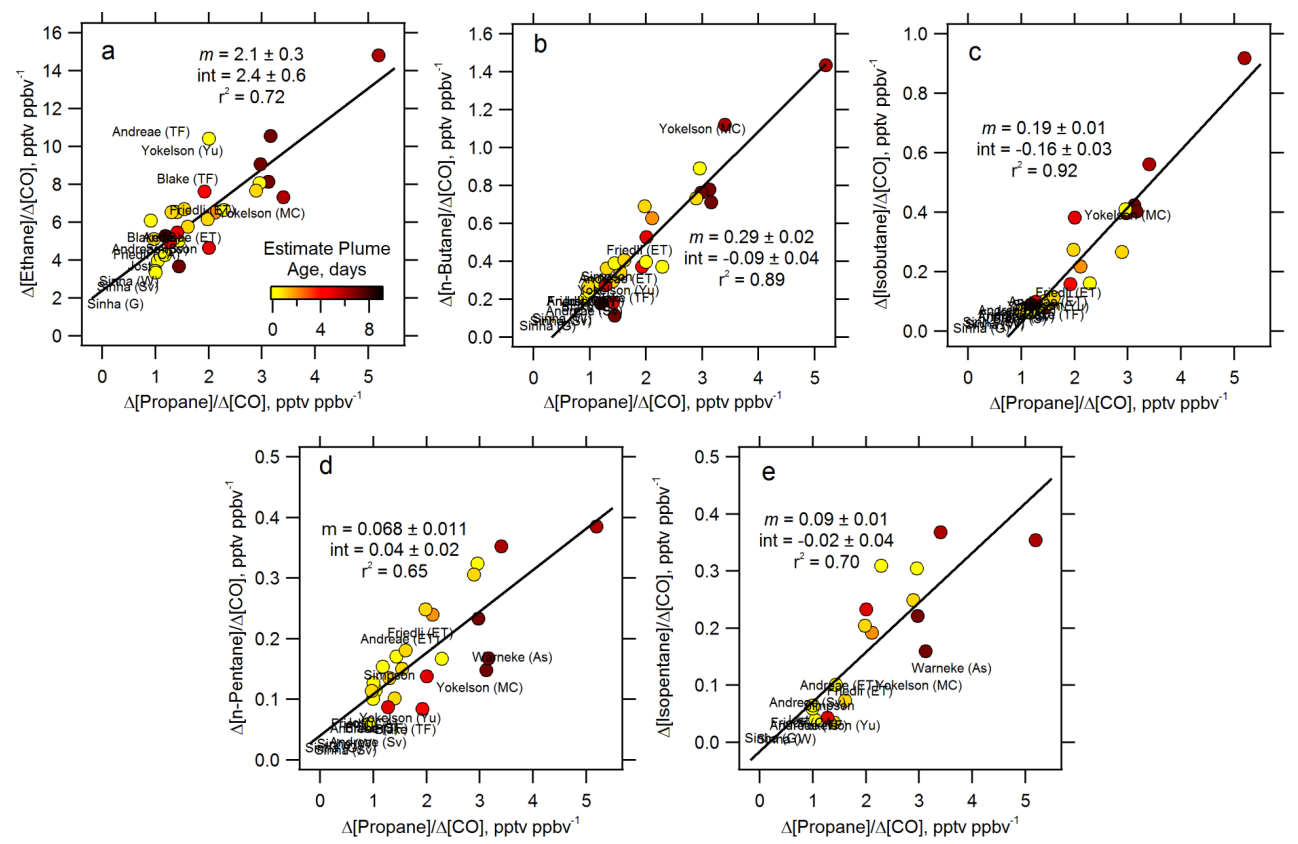

Fig. 8. Comparison plots of the NEMRs to CO observed during ARCTAS for several light alkanes against propane determined using the WAS data, colored by the estimated BB plume age. Also shown are the corresponding literature NEMR ratios listed in Table 4. Linear least-squares fits to the ARCTAS data are shown, with details for the fits listed on each full-scale plot.
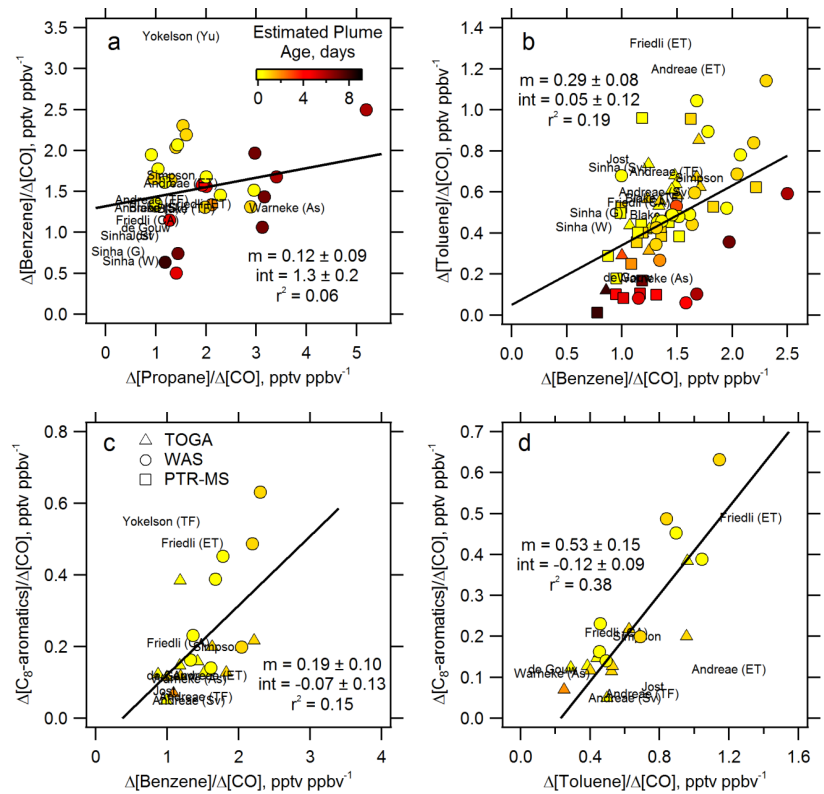

Fig. 9. Similar to Fig. 8, comparison plots of the NEMRs to CO observed during ARCTAS for aromatic hydrocarbons and propane. Comparisons using NEMRs from three instruments are shown, according to the legend in (c). Also shown are the corresponding literature NEMR ratios listed in Tables 3 and 4.

is again very little correlation, with an overall $r^{2}$ of 0.19 . Nonetheless, there is a trend towards lower ratios of toluene to benzene as the plume ages, consistent with the shorter atmospheric lifetime of toluene. Similarly, in Fig. 9c, there is very little correlation between the NEMRs for the $\mathrm{C}_{8}$ aromatics and benzene, with an $r^{2}$ of 0.15 . However, as shown in Fig. 9d, a comparison of NEMRs for the $\mathrm{C}_{8}$ aromatics against toluene, a linear fit to the combined TOGA and WAS data has a slope of $0.53 \pm 0.15$ with an $r^{2}$ of 0.38 , likely due to a combination of related emissions and chemical removal processes. The enhancements of aromatic hydrocarbons are thus somewhat correlated to each other, but to a lesser degree when measured downwind due to relatively fast removal mechanisms. There is little correlation between the emissions of aromatic hydrocarbons and alkanes.

Finally, Fig. 10 shows similar plots of comparisons of the NEMRs to CO for some of the oxygenated NMOCs observed during ARCTAS against the acetone to CO NEMR, as well as a comparison of the NEMRs of acetone and propane. For these plots, only data from younger plumes estimated to be one day or less in age are shown, including literature data. In Fig. 10, the ARCTAS data are colored by the plume MCE. A similar analysis of the alkane and aromatic NEMRs indicated no correlation with MCE. Figure 10a shows that the NEMRs to $\mathrm{CO}$ for the WAS acetone and propane are correlated, with a slope of $4.6 \pm 1.4$, and an $r^{2}$ value of 0.55 . Figure $10 \mathrm{~b}$ shows a comparison of methanol to acetone NEMRs to CO observed during ARCTAS from TOGA, WAS and PTR-MS. A linear fit to all the observed data indicates good correlation 
between methanol and acetone with a slope of $3.4 \pm 0.4$ and an $r^{2}$ value of 0.72 . There is also an apparent dependence on the MCE for both methanol and acetone, with larger enhancements to $\mathrm{CO}$ of both compounds in plumes with MCEs indicating flaming combustion sources. A modest correlation between MCE and methanol enhancements relative to $\mathrm{CO}$ was also seen by Yokelson et al. (2009), but in that case, $\Delta\left[\mathrm{CH}_{3} \mathrm{OH}\right] / \Delta[\mathrm{CO}]$ typically decreased with increasing MCEs between 0.892 and 0.956. Since dilution with background air results in a higher observed MCE (since background air has an MCE of approximately 0.9997), uncertainties are larger for observed MCEs in BB plumes one day in age or greater. Overall, however, the strongest MCE dependence in the ARCTAS data is in the 0.80-0.90 range, with a potential maximum in the emissions at MCEs near 0.90, so these findings are not incompatible.

In a comparison of ethanol versus acetone NEMRs (not shown), the data are more scattered than in Fig. 10b, but again the emissions of the two oxygenated NMOC are somewhat correlated with an $r^{2}$ of 0.40 . As with methanol and acetone, $\Delta[$ ethanol $] / \Delta[\mathrm{CO}]$ typically increased with increasing MCE. Likewise, a comparison plot for MEK versus acetone NEMRs in Fig. 10c indicates the enhancements to $\mathrm{CO}$ are somewhat correlated with each other $\left(r^{2}=0.53\right)$ and with the MCE. Although the published ratio from Simpson et al. (2011), determined using WAS ARCTAS data with slightly different plume selection criteria, is in agreement with the linear fit, the literature values from Friedli et al. (2001) and Yokelson et al. (2009) and one of the ARCTAS TOGA data points deviate significantly from the linear regression fit, indicating that there are other factors to consider. Nevertheless, the majority of the points in this plot also point towards a trend of increasing NEMR with MCEs closer to the flaming stage.

In Fig. 10d and e, the data are significantly more scattered for both formaldehyde and acetaldehyde NEMRs against acetone NEMRs, with less dependence for aldehyde enhancements to CO on MCE. In a laboratory burn, Burling et al. (2010) showed that formaldehyde emissions tend to peak early during the burn in a more vigorous flaming stage, and although it is still emitted during later mixed flaming/smoldering stages, the emission ratios to $\mathrm{CO}$ are naturally more variable than ratios of NMOC that are emitted from burn stages similar to CO. However, as shown in Fig. 10f, a comparison of formaldehyde to acetaldehyde NEMRs to CO, although there is not a clear dependence on plume MCE, the enhancements of these two aldehydes in observed fire plumes are well-correlated to each other with an $r^{2}$ of 0.70 .

\subsection{Evolution of NMOCs in biomass burning plumes}

Gas-phase NMOCs are often loosely classified as primary NMOCs and secondary NMOCs. Primary NMOCs consist of NMHC and oxygenated NMOCs emitted directly into the atmosphere, while secondary NMOCs include oxygenated NMOCs, organic nitrates, and particulate organic matter, and are formed in the troposphere from the photo-oxidization of primary NMOCs. Many oxygenated NMOCs are both primary and secondary NMOC, but uncertainties regarding the relative contribution to the total oxygenated NMOC for a given species based on source type and photochemical age remain. Further, many NMOCs cannot be quantified using currently-available techniques (Warneke et al., 2011), leading to additional uncertainties regarding the relative contribution of oxygenated NMOC to total NMOC. Nevertheless, the evolution of oxygenated NMOCs in anthropogenic air masses and biomass burning plumes has been investigated numerous times over the last decade. Both de Gouw et al. (2005) and Apel et al. (2010) showed that secondary production of acetaldehyde can be important in urban outflow. As well, oxygenated NMOC production may be significant in BB plumes based on comparisons of observed acetaldehyde to benzene NEMRs in aged boreal forest fire plumes (de Gouw et al., 2006), and from observed growth of organic acids in slightly aged BB plumes (Yokelson et al., 2009). As discussed in Sect. 3.3.3, acetone NEMRs to CO have been reported to increase in aging fire plumes over short timescales (i.e. hours) (Jost et al., 2003), and literature NEMRs from aged BB plumes seem to indicate that over longer timescales, acetone NEMRs to $\mathrm{CO}$ continue to increase.

The evolution of NMOCs within BB plumes observed during ARCTAS was investigated using the NCAR Master Mechanism. Two sets of initial conditions were used to model the chemical evolution of trace gas-phase chemical species over 2.5 days within a BB plume. The initial conditions were based on observations from ARCTAS-CARB and ARCTAS-B of a fresh BB plume in California (CAL BB; a 10-min period during plume 18) and a fresh BB plume from a boreal-forested area in Saskatchewan (CAN BB; plume 25). The CAL BB model starting conditions had higher absolute concentrations of gas-phase species of interest than the CAN $\mathrm{BB}$ model run, with $4 \mathrm{x}$ larger $\mathrm{CO}$ and NMOCs, an order of magnitude larger $\mathrm{NO}_{\mathrm{x}}, 1.6 \times$ the $\mathrm{O}_{3}$, and $1.4 \times$ the $\mathrm{OH}$. The higher $\mathrm{NO}_{\mathrm{x}}$ and $\mathrm{O}_{3} \mathrm{CAL} \mathrm{BB}$ starting conditions are consistent with the more anthropogenically-influenced background air in California compared to Saskatchewan. Both models runs were initialized at noon on day 1 .

Although NMOC mixing ratios were $4 \times$ larger in the CAL BB simulation, the relative mixing ratios of different classes of NMOCs in these starting conditions are similar, as shown in Fig. 11a and b; in both the CAN BB and CAL BB initial conditions, oxygenated NMOCs comprise approximately $65 \%$ of the NMOCs in the plume. In contrast, Fig. 11c, the distribution of the same classes of NMOCs observed in an urban region of California during ARCTAS, shows that oxygenated NMOCs comprise less than $50 \%$ of observed NMOCs. Ratios of oxygenated NMOC to total NMOC ranging from $60-80 \%$ are typical for BB emissions (Yokelson et al., 1999, 2008, 2009; Burling et al., 2010), 

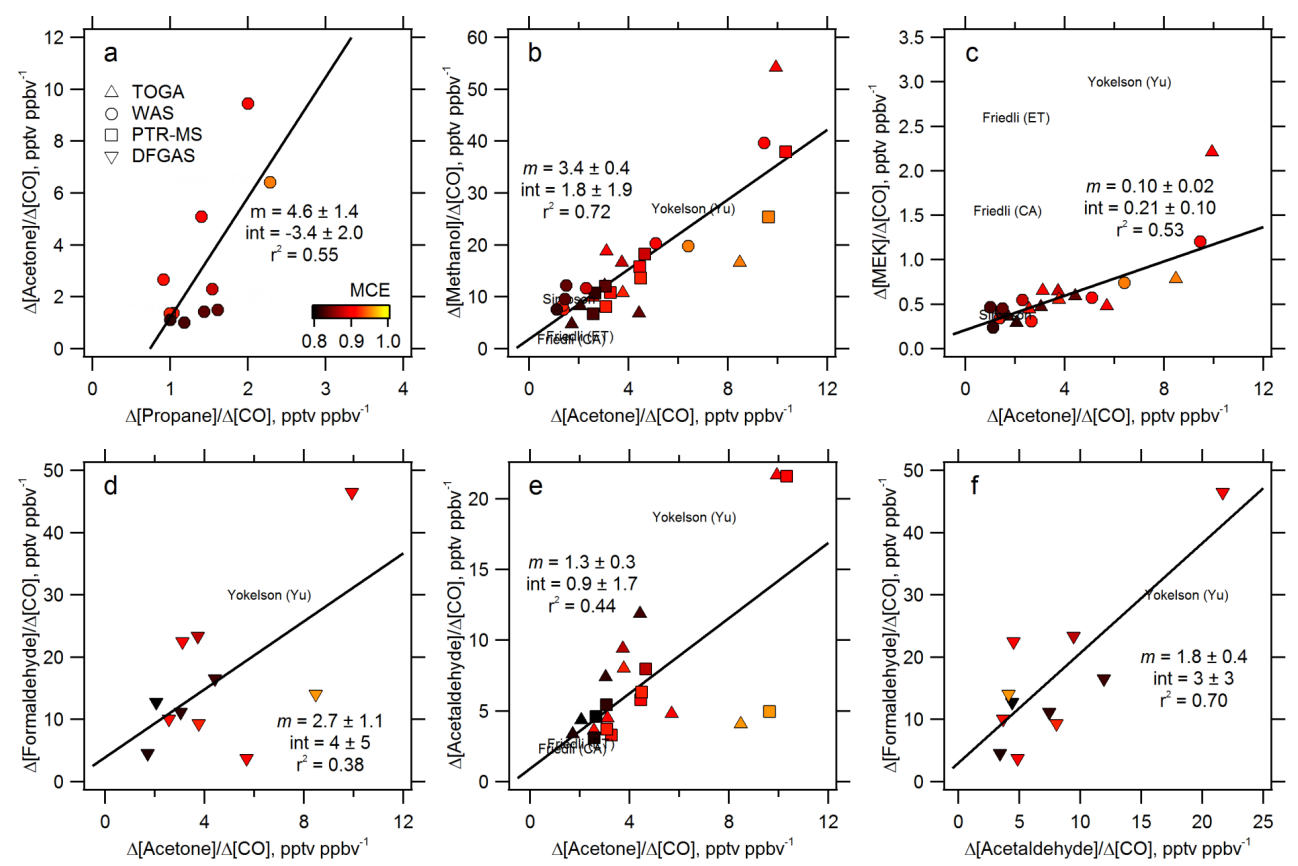

Fig. 10. Similar to Figs. 8 and 9, comparison plots of the NEMRs to CO observed during ARCTAS for oxygenated NMOC, colored by plume MCE. Also shown are the corresponding literature NEMR ratios listed in Table 3. In (d) and (f), formaldehyde NEMRs to CO from ARCTAS are plotted against NEMRs determined using TOGA data.

and are higher than oxygenated NMOC/NMOC ratios observed in air masses primarily influenced by fossil fuel burning emissions (typically less than $50 \%$, de Gouw et al., 2009; Apel et al., 2010). It should be noted that these percentages rely heavily on the compounds included. Compound classes in Fig. 11 are comprised of $\mathrm{C}_{2}-\mathrm{C}_{6}$ alkanes (alkanes); $\mathrm{C}_{2}-\mathrm{C}_{4}$ alkenes, isoprene, $\alpha$ - and $\beta$-pinene (alkenes); ethyne and propyne (alkynes) $\mathrm{C}_{6}-\mathrm{C}_{8}$ aromatics (aromatics); $\mathrm{C}_{1}-$ $\mathrm{C}_{4}$ aldehydes (aldehydes); acetone, MEK, MVK (ketones); and $\mathrm{C}_{1}-\mathrm{C}_{2}$ alcohols (alcohols). Although organic acids are known to be emitted in significant amounts from BB (Yokelson et al., 1999, 2003; Burling et al., 2010), because they were not measured on the DC- 8 during ARCTAS, they were not included in the model simulations. Inclusion of other compounds (e.g., alkyl nitrates and halogenated NMOCs) would also change the absolute ratios, but the relative differences between the oxygenated NMOC/NMOC ratios in the two BB plumes and the anthropogenically-influenced air masses would still exist. With smaller relative concentrations of NMHC precursors and a higher proportion of oxygenated NMOCs, the chemistry within BB plumes will differ from that of anthropogenic plumes.

Figure 12 shows plots of the modeled changes in NEMRs to CO over 2.5 days for both model runs for several NMOCs. For comparison, observed NEMRs to $\mathrm{CO}$ for formaldehyde, and TOGA-observed NMOC in BB plumes estimated to be less than three days in age are also plotted in Fig. 12 according to the estimated BB plume age. From the MM

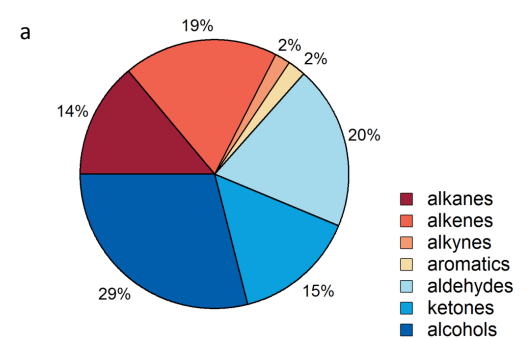

b
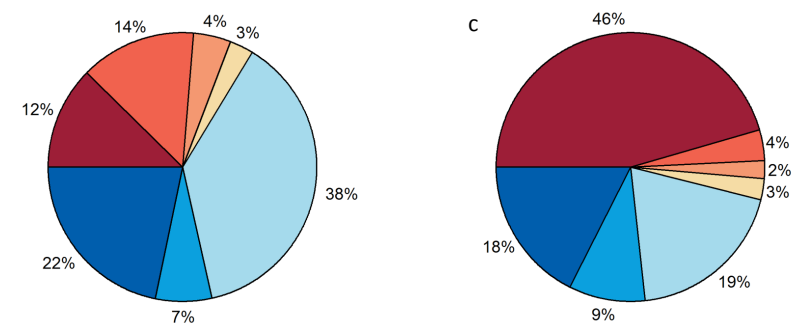

Fig. 11. Measured NMOC distributions based on the sums of mixing ratios in each compound class from selected ARCTAS observations in fresh (a) Canadian BB, (b) Californian BB and (c) urban emissions; (a) and (b) are the initial conditions used for the NCAR Master Mechanism box modeling.

model results for both the CAN BB and CAL BB simulations, the mixing ratios of low molecular weight carbonyls (i.e. formaldehyde, acetaldehyde, acetone and MEK) and alcohols (i.e. methanol and ethanol) primarily decrease with 


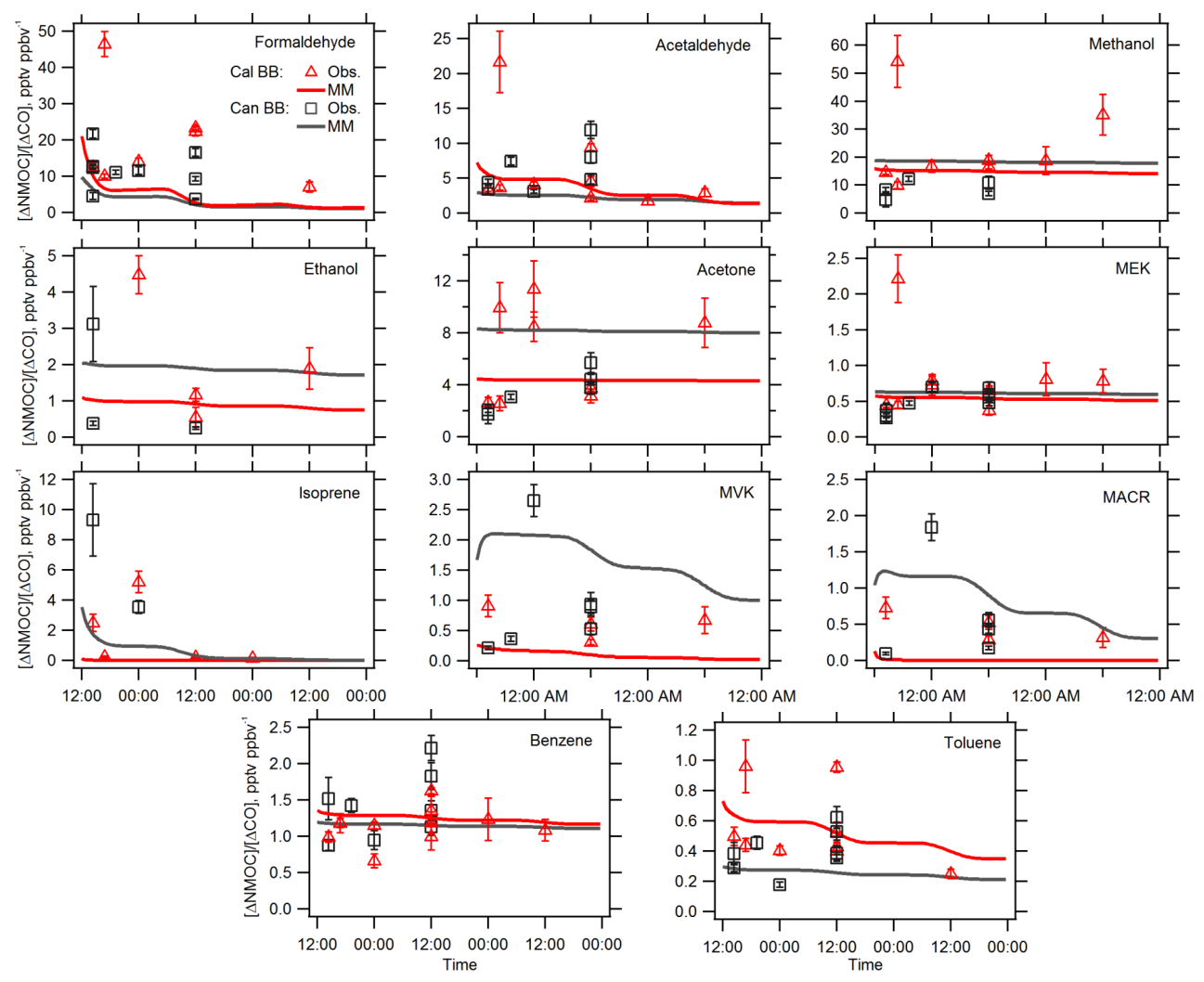

Fig. 12. Plots of Master Mechanism (MM) modeled and observed NEMRs to CO for 11 NMOCs. Points are the ARCTAS-observed NEMRs to $\mathrm{CO}$ for BB plumes estimated to be aged 3 days or less, as measured by DFGAS (formaldehyde) and TOGA (all others), with error bars as described for Fig. 7.

age in the $\mathrm{BB}$ plumes, indicating the loss reactions of these compounds are generally greater than any production terms within the plumes. The only exceptions to this are very slight increases of mixing ratios of formaldehyde and acetaldehyde in the late afternoon and evening of day 1 and 2 after the initial drop in daytime mixing ratios for these species when their destruction is outpacing their production. In the CAN BB model run, the isoprene oxidation products MVK and MACR both increase for approximately $3-4 \mathrm{~h}$ while isoprene is present in significant amounts (i.e. $>300$ pptv), then decrease for the remainder of the simulation. All ratios to $\mathrm{CO}$ for the NMOC subset shown here are predicted to decrease over a period of 2.5 days, with the exception of the MVK and MACR NEMRs during the first few hours of the CAN BB model run. As expected, for short-lived compounds that are not produced photochemically (e.g. isoprene and toluene, with tropospheric lifetimes approximately 1 day or less), there is a fairly rapid daylight-dependent decrease in the modeled NEMRs, while for some of the oxygenated NMOCs with tropospheric lifetimes approximately 1 week or greater (i.e. methanol, acetone, MEK) the modeled NEMRs remain fairly constant with time, decreasing only slightly over 2.5 days.
For most NMOCs in Fig. 12, the observed NEMRs in relatively young BB plumes ( $<1$ day) are highly variable, with some observed NEMRs significantly larger than the conditions chosen for the model runs. It should be noted, however, that the observed NEMRs are not all from the same fire, and may therefore originate from fires with different emission ratios. By the time the plumes are estimated to be 1.5 to 2 days in age, the majority of the observed NEMRs are similar to the modeled NEMRs, possibly due in part to lower relative mixing ratios. However, for acetone, methanol, MEK, and to a lesser extent, benzene and ethanol, the NEMRs to CO are not predicted to change significantly over 2.5 days, suggesting that any variability in fresh BB emissions is likely to be maintained in an aging plume. Although there are differences in ozone production and $\mathrm{OH}$ reactivities within the two plumes, which will be explored further in Part 2 (Hornbrook et al., 2011), in general the relative changes in NEMRs to CO for observed NMOC are not predicted to differ significantly between the two cases. 


\section{Conclusions}

During the ARCTAS campaign, instruments on board the NASA DC-8 measured the mixing ratios of a large number of NMOCs in BB plumes originating from several fires burning in Asia and North America ranging from fresh emissions to plumes over a week in age. Of the NMOCs measured by TOGA, several were co-observed by other measurement techniques. There was very good agreement between the instruments for the majority of the flights and, in general, quantitative differences between the systems can be explained by the different sampling integration times of the instruments, particularly in highly variable air masses such as those encountered in fresh BB emissions.

For our analysis, BB plumes encountered by the DC- 8 were grouped by flight, chemical composition, and source region into 40 individual plumes for analysis. NEMRs to $\mathrm{CO}$ were determined for $\mathrm{HCN}$, acetonitrile, several NMHC and oxygenated NMOCs for each of the plumes, and compared to literature values. Overall, the NEMRs observed during ARCTAS showed good agreement with literature values for most NMOCs. For some compounds, however, such as ethanol, MVK and MACR, very few literature values have been published. The ethanol to CO NEMRs observed during ARCTAS range from values similar to the previouslyreported NEMRs $\left(0.1-0.15 \mathrm{pptv}_{\mathrm{ppbv}}{ }^{-1}\right)$ to well over an order of magnitude larger $\left(4.5 \pm 0.5 \mathrm{pptv}_{\mathrm{ppbv}}^{-1}\right)$. Our findings show that ethanol emissions from fires may be significantly larger than previously thought.

Although significant variability exists in observed NEMRs from both ARCTAS and previous field studies, some NMOCs have NEMRs to CO that are highly correlated. This was clearly shown for the light $\mathrm{C}_{2}-\mathrm{C}_{5}$ alkane NEMRs to $\mathrm{CO}$ observed during ARCTAS, with the strongest correlation between the $\mathrm{C}_{2}-\mathrm{C}_{4}$ alkanes and slightly higher variability for the $\mathrm{C}_{5}$ alkanes, primarily due to lower mixing ratios and measurement uncertainties. In general, these correlations are linear and are attributed to correlated emissions rather than chemical loss. Correlations are also evident in the emissions of many of the oxygenated NMOC as well, in particular for methanol, acetone and MEK.

Results from Master Mechanism box model simulations of the evolution of two BB plumes, one based on observed Canadian BB and the other based on Californian BB, were compared to ARCTAS-observed NEMRs for BB in these regions. The initial concentrations for the Californian $\mathrm{BB}$ plume indicated more anthropogenically-influenced background conditions than that of the Canadian BB plume, with $10 \times$ greater $\mathrm{NO}_{\mathrm{x}}, 1.6 \times$ greater $\mathrm{O}_{3}$ concentrations, and $4 \times$ greater NMOC and CO concentrations. All observed oxygenated NMOC mixing ratios are predicted to decrease over a period of 2.5 days within the plumes, although the concentrations of MVK and MACR are predicted to increase initially in the Canadian BB plume while isoprene is still present in significant amounts ( $>300 \mathrm{pptv})$. As well, all
NEMRs to $\mathrm{CO}$ for these oxygenated NMOCs are predicted to decrease over the 2.5 days. Although they generally decrease with time, the time-dependences of the modeled NEMRs of acetone, methanol and MEK, and to a smaller extent, ethanol, are relatively flat, indicating that much of the variability in observed NEMRs to CO in BB plumes for these compounds is due to variability in the emissions.

Acknowledgements. HCN data were provided courtesy of Paul Wennberg, John Crounse and Andreas Kürten at the California Institute of Technology. The authors thank the crew and support team for the NASA DC-8 aircraft, and Isobel Simpson, Simone Tilmes and Thomas Karl for helpful comments and discussion. The authors gratefully acknowledge the financial support of NASA (Grant No. X08AD33G). PTR-MS measurements were supported by the Austrian Research Promotion Agency (FFG-ALR) and the Tiroler Zukunftstiftung, and were carried out with the help of M. Graus, A. Hansel and T. D. Maerk. The National Center for Atmospheric Research is sponsored by the National Science Foundation. Any opinions, findings and conclusions or recommendations expressed in the publication are those of the authors and do not necessarily reflect the views of the National Science Foundation.

Edited by: P. Quinn

\section{References}

Akagi, S. K., Yokelson, R. J., Wiedinmyer, C., Alvarado, M. J., Reid, J. S., Karl, T., Crounse, J. D., and Wennberg, P. O.: Emission factors for open and domestic biomass burning for use in atmospheric models, Atmos. Chem. Phys., 11, 4039-4072, doi:10.5194/acp-11-4039-2011, 2011.

Andreae, M. O. and Merlet, P.: Emission of trace gases and aerosols from biomass burning, Global Biogeochem. Cy., 15, 955-966, doi:10.1029/2000GB001382, 2001.

Apel, E. C., Calvert, J. G., and Fehsenfeld, F. C.: The Nonmethane Hydrocarbon Intercomparison Experiment (NOMHICE): Tasks 1 and 2, J. Geophys. Res., 99, 1665116664, doi:10.1029/94JD00086, 1994.

Apel, E. C., Calvert, J. G., Gilpin, T. M., Fehsenfeld, F. C., Parrish, D. D., and Lonneman, W. A.: The Nonmethane Hydrocarbon Intercomparison Experiment (NOMHICE): Task 3, J. Geophys. Res., 104, 16651-16664, doi:10.1029/1999JD900793, 1999.

Apel, E. C., Hills, A. J., Lueb, R., Zindel, S., Eisele, S., and Riemer, D. D.: A fast-GC/MS system to measure $\mathrm{C}_{2}$ to $\mathrm{C}_{4}$ carbonyls and methanol aboard aircraft, J. Geophys. Res., 108, 8794, doi:10.1029/2002JD003199, 2003.

Apel, E. C., Emmons, L. K., Karl, T., Flocke, F., Hills, A. J., Madronich, S., Lee-Taylor, J., Fried, A., Weibring, P., Walega, J., Richter, D., Tie, X., Mauldin, L., Campos, T., Weinheimer, A., Knapp, D., Sive, B., Kleinman, L., Springston, S., Zaveri, R., Ortega, J., Voss, P., Blake, D., Baker, A., Warneke, C., Welsh-Bon, D., de Gouw, J., Zheng, J., Zhang, R., Rudolph, J., Junkermann, W., and Riemer, D. D.: Chemical evolution of volatile organic compounds in the outflow of the Mexico City Metropolitan area, Atmos. Chem. Phys., 10, 2353-2375, doi:10.5194/acp-10-23532010, 2010. 
Apel, E. C., Olson, J. R., Crawford, J. H., Hornbrook, R. S., Hills, A. J., Cantrell, C. A., Emmons, L. K., Knapp, D. J., Hall, S., Mauldin III, R. L., Weinheimer, A. J., Fried, A., Blake, D. R., Crounse, J. D., Clair, J. M. St., Wennberg, P. O., Diskin, G. S., Fuelberg, H. E., Wisthaler, A., Mikoviny, T., Brune, W., and Riemer, D. D.: Impact of the deep convection of isoprene and other reactive trace species on radicals and ozone in the upper troposphere, Atmos. Chem. Phys. Discuss., 11, 27243-27284, doi:10.5194/acpd-11-27243-2011, 2011.

Atkinson, R.: Atmospheric chemistry of VOCs and $\mathrm{NO}_{\mathrm{x}}$, Atmos. Environ., 34, 2063-2101, doi:10.1016/S1352-2310(99)00460-4, 2000.

Atkinson, R. and Arey, J.: Atmospheric degradation of volatile organic compounds, Chem. Rev., 103, 4605-4638, doi:10.1021/cr0206420, 2003.

Baum, M. M., Moss, J. A., Pastel, S. H., and Poskrebyshev, G. A.: Hydrogen cyanide exhaust emissions from in-use motor vehicles, Environ. Sci. Tech., 41, 857-862, doi:10.1021/es061402v, 2007.

Blake, D. R., Smith Jr., T. W., Chen, T.-Y., Whipple, W. J., and Rowland, F. S.: Effects of biomass burning on summertime nonmethane hydrocarbon concentrations in the Canadian wetlands, J. Geophys. Res., 99, 1699-1719, doi:10.1029/93JD02598, 1994.

Blake, N. J., Blake, D. R., Sive, B. C., Chen, T. Y., Rowland, F. S., Collins, J. E., Sachse, G. W., and Anderson, B. E.: Biomass burning emissions and vertical distribution of atmospheric methyl halides and other reduced carbon gases in the South Atlantic region, J. Geophys. Res., 101, 24151-24164, doi:10.1029/96JD00561, 1996

Burling, I. R., Yokelson, R. J., Griffith, D. W. T., Johnson, T. J., Veres, P., Roberts, J. M., Warneke, C., Urbanski, S. P., Reardon, J., Weise, D. R., Hao, W. M., and de Gouw, J.: Laboratory measurements of trace gas emissions from biomass burning of fuel types from the southeastern and southwestern United States, Atmos. Chem. Phys., 10, 11115-11130, doi:10.5194/acp10-11115-2010, 2010.

Christian, T. J., Kleiss, B., Yokelson, R. J., Holzinger, R., Crutzen, P. J., Hao, W. M., Saharjo, B. H., and Ward, D. E.: Comprehensive laboratory measurements of biomass-burning emissions: 1 . Emissions from Indonesian, African, and other fuels, J. Geophys. Res., 108, 4719, doi:10.1029/2003JD003704, 2003.

Christian, T. J., Kleiss, B., Yokelson, R. J., Holzinger, R., Crutzen, P. J., Hao, W. M., Shirai, T., and Blake, D. R.: Comprehensive laboratory measurements of biomass-burning emissions: 2. First intercomparison of open-path FTIR, PTRMS, and GC- MS/FID/ECD, J. Geophys. Res., 109, D02311, doi:10.1029/2003JD003874, 2004.

Christian, T. J., Yokelson, R. J., Carvalho, J. A., Jr., Griffith, D. W. T., Alvarado, E. C., Santos, J. C., Neto, T. G. S., Gurgel Veras, C. A., and Hao, W. M.: The tropical forest and fire emissions experiment: Trace gases emitted by smoldering logs and dung from deforestation and pasture fires in Brazil, J. Geophys. Res., 112, D18308, doi:10.1029/2006JD008147, 2007.

Ciccioli, P., Brancaleoni, E., Frattoni, M., Cecinato, A., and Pinciarelli, L.: Determination of volatile organic compounds (VOC) emitted from biomass burning of Mediterranean vegetation species by GC-MS, Anal. Lett., 34, 937-955, doi:10.1081/AL100103604, 2001.

Colarco, P. R., Schoeberl, M. R., Doddridge, B. G., Marufu, L. T.,
Torres, O., and Welton, E. J.: Transport of smoke from Canadian forest fires to the surface near Washington, D. C.: Injection height, entrainment, and optical properties, J. Geophys. Res., 109, D06203, doi:10.1029/2003JD004248, 2004.

Colman, J. J., Swanson, A. L., Meinardi, S., Sive, B. C., Blake, D. R., and Rowland, F. S.: Description of the analysis of a wide range of volatile organic compounds in whole air samples collected during PEM-Tropics A and B, Anal. Chem., 73, 37233731, doi:10.1021/ac010027g, 2001.

Crounse, J. D., McKinney, K. A., Kwan, A. J., and Wennberg, P. O.: Measurement of gas-phase hydroperoxides by chemical ionization mass spectrometry, Anal. Chem., 78, 6726-6732, doi:10.1021/ac0604235, 2006.

Crounse, J. D., DeCarlo, P. F., Blake, D. R., Emmons, L. K., Campos, T. L., Apel, E. C., Clarke, A. D., Weinheimer, A. J., McCabe, D. C., Yokelson, R. J., Jimenez, J. L., and Wennberg, P. O.: Biomass burning and urban air pollution over the Central Mexican Plateau, Atmos. Chem. Phys., 9, 4929-4944, doi:10.5194/acp-9-4929-2009, 2009.

Damoah, R., Spichtinger, N., Forster, C., James, P., Mattis, I., Wandinger, U., Beirle, S., Wagner, T., and Stohl, A.: Around the world in 17 days - hemispheric-scale transport of forest fire smoke from Russia in May 2003, Atmos. Chem. Phys., 4, 13111321, doi:10.5194/acp-4-1311-2004, 2004.

de Gouw, J. A. and Warneke, C.: Measurements of volatile organic compounds in the earth's atmosphere using proton-transferreaction mass spectrometry, Mass Spectrom. Rev., 26, 223-257, doi:10.1002/mas.20119, 2007.

de Gouw, J. A., Warneke, C., Parrish, D. D., Holloway, J. S., Trainer, M., and Fehsenfeld, F. C.: Emission sources and ocean uptake of acetonitrile $\left(\mathrm{CH}_{3} \mathrm{CN}\right)$ in the atmosphere, J. Geophys. Res., 108, 4329, doi:10.1029/2002JD002897, 2003.

de Gouw, J. A., Middlebrook, A. M., Warneke, C., Goldan, P. D., Kuster, W. C., Roberts, J. M., Fehsenfeld, F. C., Worsnop, D. R., Canagaratna, M. R., Pszenny, A. A. P., Keene, W. C., Marchewka, M., Bertman, S. B., and Bates, T. S.: Budget of organic carbon in a polluted atmosphere: Results from the New England Air Quality Study in 2002, J. Geophys. Res., 110, D16305, doi:10.1029/2004JD005623, 2005.

de Gouw, J. A., Warneke, C., Stohl, A., Wollny, A. G., Brock, C. A., Cooper, O. R., Holloway, J. S., Trainer, M., Fehsenfeld, F. C., Atlas, E. L., Donnelly, S. G., Stroud, V., and Lueb, A.: Volatile organic compounds composition of merged and aged forest fire plumes from Alaska and western Canada, J. Geophys. Res., 111, D10303, doi:10.1029/2005JD006175, 2006.

de Gouw, J. A., Welsh-Bon, D., Warneke, C., Kuster, W. C., Alexander, L., Baker, A. K., Beyersdorf, A. J., Blake, D. R., Canagaratna, M., Celada, A. T., Huey, L. G., Junkermann, W., Onasch, T. B., Salcido, A., Sjostedt, S. J., Sullivan, A. P., Tanner, D. J., Vargas, O., Weber, R. J., Worsnop, D. R., Yu, X. Y., and Zaveri, R.: Emission and chemistry of organic carbon in the gas and aerosol phase at a sub-urban site near Mexico City in March 2006 during the MILAGRO study, Atmos. Chem. Phys., 9, 3425-3442, doi:10.5194/acp-9-3425-2009, 2009.

Duck, T. J., Firanski, B. J., Millet, D. B., Goldstein, A. H., Allan, J., Holzinger, R., Worsnop, D. R., White, A. B., Stohl, A., Dickinson, C. S., and van Donkelaar, A.: Transport of forest fire emissions from Alaska and the Yukon Territory to Nova Scotia during summer 2004, J. Geophys. Res., 112, D10S44, 
doi:10.1029/2006JD007716, 2007.

Fisher, J. A., Jacob, D. J., Purdy, M. T., Kopacz, M., Le Sager, P., Carouge, C., Holmes, C. D., Yantosca, R. M., Batchelor, R. L., Strong, K., Diskin, G. S., Fuelberg, H. E., Holloway, J. S., Hyer, E. J., McMillan, W. W., Warner, J., Streets, D. G., Zhang, Q., Wang, Y., and Wu, S.: Source attribution and interannual variability of Arctic pollution in spring constrained by aircraft (ARCTAS, ARCPAC) and satellite (AIRS) observations of carbon monoxide, Atmos. Chem. Phys., 10, 977-996, doi:10.5194/acp-10-977-2010, 2010.

Friedli, H. R., Atlas, E., Stroud, V. R., Giovanni, L., Campos, T., and Radke, L. F.: Volatile organic trace gases emitted from North American wildfires, Global Biogeochem. Cy., 15, 435452, doi:10.1029/2000GB001328, 2001.

Fromm, M., Alfred, J., Hoppel, K., Hornstein, J., Bevilacqua, R., Shettle, E., Servranckx, R., Li, Z. Q. and Stocks, B.: Observations of boreal forest fire smoke in the stratosphere by POAM III, SAGE II, and lidar in 1998, Geophys. Res. Lett., 27, 1407-1410, doi:10.1029/1999GL011200, 2000.

Fuelberg, H. E., Harrigan, D. L., and Sessions, W.: A meteorological overview of the ARCTAS 2008 mission, Atmos. Chem. Phys., 10, 817-842, doi:10.5194/acp-10-817-2010, 2010.

Harvey, C. A., Garbe, R. J., Baines, T. M., Somers, J. H., Hellman, K. H., and Carey, P. M.: A study of the potential impact of some unregulated motor vehicle emissions, SAE Tech. Pap. Ser., 830987, doi:10.4271/830987, 1983.

Holzinger, R., Williams, J., Salisbury, G., Klüpfel, T., de Reus, M., Traub, M., Crutzen, P. J., and Lelieveld, J.: Oxygenated compounds in aged biomass burning plumes over the Eastern Mediterranean: evidence for strong secondary production of methanol and acetone, Atmos. Chem. Phys., 5, 39-46, doi:10.5194/acp-5-39-2005, 2005.

Hornbrook, R. S., Blake, D. R., Brune, W., Diskin, G. S., Flocke, F., Fuelberg, H. E., Knapp, D. J., Mauldin III, R. L., Montzka, D. D., Pollack, I. B., Vay, S. A., Weinheimer, A. J., Hills, A., Riemer, D. D., and Apel, E. C.: Observations of Volatile Organic Compounds during ARCTAS - Part 2: Contrasting Biomass Burning and Anthropogenic Emissions Sources, to be submitted to Atmos. Chem. Phys. Discuss., 2011.

Jacob, D. J., Crawford, J. H., Maring, H., Clarke, A. D., Dibb, J. E., Ferrare, R. A., Hostetler, C. A., Russell, P. B., Singh, H. B., Thompson, A. M., Shaw, G. E., McCauley, E., Pederson, J. R., and Fisher, J. A.: The ARCTAS aircraft mission: design and execution, Atmos. Chem. Phys. Discuss., 9, 17073-17123, doi:10.5194/acpd-9-17073-2009, 2009.

Jost, C., Trentmann, J., Sprung, D., Andreae, M. O., McQuaid, J. B., and Barjat, H.: Trace gas chemistry in a young biomass burning plume over Namibia: Observations and model simulations, J. Geophys. Res., 108, 8482, doi:10.1029/2002JD002431, 2003.

Jost, H. J., Drdla, K., Stohl, A., Pfister, L., Loewenstein, M., Lopez, J. P., Hudson, P. K., Murphy, D. M., Cziczo, D. J., Fromm, M., Bui, T. P., Dean-Day, J., Gerbig, C., Mahoney, M. J., Richard, E. C., Spichtinger, N., Pittman, J. V., Weinstock, E. M., Wilson, J. C., and Xueref, I.: In-situ observations of mid-latitude forest fire plumes deep in the stratosphere, Geophys. Res. Lett., 31, L11101, doi:10.1029/2003GL019253, 2004.

Karl, T. G., Christian, T. J., Yokelson, R. J., Artaxo, P., Hao, W. M., and Guenther, A.: The Tropical Forest and Fire Emissions Experiment: method evaluation of volatile organic com- pound emissions measured by PTR-MS, FTIR, and GC from tropical biomass burning, Atmos. Chem. Phys., 7, 5883-5897, doi:10.5194/acp-7-5883-2007, 2007.

Katzenstein, A. S., Doezema, L. A., Simpson, I. J., Blake, D. R., and Rowland, F. S.: Extensive regional atmospheric hydrocarbon pollution in the southwestern United States, P. Natl. Acad. Sci. USA, 100, 11975-11979, doi:10.1073/pnas.1635258100, 2003.

Kleb, M. M., Chen, G., Crawford, J. H., Flocke, F. M., and Brown, C. C.: An overview of measurement comparisons from the INTEX-B/MILAGRO airborne field campaign, Atmos. Meas. Tech., 4, 9-27, doi:10.5194/amt-4-9-2011, 2011.

Levine, J. S.: Global biomass burning: A case study of the gaseous and particulate emissions released to the atmosphere during the 1997 fires in Kalimantan and Sumatra, Indonesia, in: Biomass Burning and Its Inter-Relationships with the Climate System, edited by:Innes, J. L., Beniston, M., and Verstraete, M. M., Kluwar Academic Publishers, Boston, 15-31, 2000.

Li, Q. B., Jacob, D. J., Bey, I., Yantosca, R. M., Zhao, Y. J., Kondo, Y., and Notholt, J.: Atmospheric hydrogen cyanide (HCN): Biomass burning source, ocean sink?, Geophys. Res. Lett., 27, 357-360, doi:10.1029/1999GL010935, 2000.

Lobert, J. M., Scharffe, D. H., Hao, W. M., and Crutzen, P. J.: Importance of biomass burning in the atmospheric budgets of nitrogen-containing gases, Nature, 346, 552-554, doi:10.1038/346552a0, 1990.

Madronich, S.: Chemical evolution of gaseous pollutants downwind of tropical megacities: Mexico City case study, Atmos. Environ., 40, 6012-6018, doi:10.1016/j.atmosenv.2005.08.047, 2006.

Madronich, S. and Calvert, J. G.: Permutation reactions of organic peroxy radicals in the troposphere, J. Geophys. Res., 95, 56975715, doi:10.1029/JD095iD05p05697, 1990.

Madronich, S. and Flocke, S: The role of solar radiation in atmospheric chemistry, in Handbook of Environmental Chemistry, edited by: Boule, P., Springer-Verlag, Heidelberg, Germany, 126, 1999.

Mason, S. A., Field, R. J., Yokelson, R. J., Kochivar, M. A., Tinsley, M. R., Ward, D. E., and Hao, W. M.: Complex effects arising in smoke plume simulations due to inclusion of direct emissions of oxygenated organic species from biomass combustion, J. Geophys. Res., 106, 12527-12539, doi:10.1029/2001JD900003, 2001.

Mason, S. A., Trentmann, J., Winterrath, T., Yokelson, R. J., Christian, T. J., Carlson, L. J., Warner, T. R., Wolfe, L. C., and Andreae, M. O.: Intercomparison of two box models of the chemical evolution in biomass-burning smoke plumes, J. Atmos. Chem., 55, 273-297, doi:10.1007/s10874-006-9039-5, 2006.

Monks, P. S., Granier, C., Fuzzi, S., Stohl, A., Williams, M. L., Akimoto, H., Amann, M., Baklanov, A., Baltensperger, U., Bey, I., Blake, N., Blake, R. S., Carslaw, K., Cooper, O. R., Dentener, F., Fowler, D., Fragkou, E., Frost, G. J., Generoso, S., Ginoux, P., Grewe, V., Guenther, A., Hansson, H. C., Henne, S., Hjorth, J., Hofzumahaus, A., Huntrieser, H., Isaksen, I. S. A., Jenkin, M. E., Kaiser, J., Kanakidou, M., Klimont, Z., Kulmala, M., Laj, P., Lawrence, M. G., Lee, J. D., Liousse, C., Maione, M., McFiggans, G., Metzger, A., Mieville, A., Moussiopoulos, N., Orlando, J. J., O’Dowd, C. D., Palmer, P. I., Parrish, D. D., Petzold, A., Platt, U., Pöschl, U., Prevot, A. S. H., Reeves, C. E., Reimann, S., Rudich, Y., Sellegri, K., Steinbrecher, R., Simpson, D., ten Brink, H., Theloke, J., van der Werf, G. R., Vautard, R., Vestreng, 
V., Vlachokostas, C., and von Glasow, R.: Atmospheric composition change - global and regional air quality, Atmos. Environ., 43, 5268-5350, doi:10.1016/j.atmosenv.2009.08.021, 2009.

Morris, G. A., Hersey, S., Thompson, A. M., Pawson, S., Nielsen, J. E., Colarco, P. R., McMillan, W. W., Stohl, A., Turquety, S., Warner, J., Johnson, B. J., Kucsera, T. L., Larko, D. E., Oltmans, S. J., and Witte, J. C.: Alaskan and Canadian forest fires exacerbate ozone pollution over Houston, Texas, on 19 and 20 July 2004, J. Geophy. Res., 111, D24S03, doi:10.1029/2006JD007090, 2006.

Raber, W. H. and Moortgat, G. K.: Photooxidation of selected carbonyl compounds in air: Methyl ethyl keton, methyl vinyl ketone , methacrolein and methylglyoxyal, in: Progress and Problems in Atmospheric Chemistry, edited by: Barker, J. R., World Scientific, New Jersey, 318-373, 1995.

Sachse, G. W., Harriss, R. C., Fishman, J., Hill, G. F., and Cahoon, D. R.: Carbon monoxide over the Amazon basin during the 1985 dry season, J. Geophys. Res., 93, 1422-1430, doi:10.1029/JD093iD02p01422, 1988.

Shim, C., Wang, Y., Singh, H. B., Blake, D. R., and Guenther, A. B.: Source characteristics of oxygenated volatile organic compounds and hydrogen cyanide, J. Geophys. Res., 112, D10305, doi:10.1029/2006JD007543, 2007.

Simpson, I. J., Blake, N. J., Barletta, B., Diskin, G. S., Fuelberg, H. E., Gorham, K., Huey, L. G., Meinardi, S., Rowland, F. S., Vay, S. A., Weinheimer, A. J., Yang, M., and Blake, D. R.: Characterization of trace gases measured over Alberta oil sands mining operations: 76 speciated $\mathrm{C}_{2}-\mathrm{C}_{10}$ volatile organic compounds (VOCs), $\mathrm{CO}_{2}, \mathrm{CH}_{4}, \mathrm{CO}, \mathrm{NO}, \mathrm{NO}_{2}, \mathrm{NO}_{\mathrm{y}}, \mathrm{O}_{3}$ and $\mathrm{SO}_{2}$, Atmos. Chem. Phys., 10, 11931-11954, doi:10.5194/acp10-11931-2010, 2010.

Simpson, I. J., Akagi, S. K., Barletta, B., Blake, N. J., Choi, Y., Diskin, G. S., Fried, A., Fuelberg, H. E., Meinardi, S., Rowland, F. S., Vay, S. A., Weinheimer, A. J., Wennberg, P. O., Wiebring, P., Wisthaler, A., Yang, M., Yokelson, R. J., and Blake, D. R.: Boreal forest fire emissions in fresh Canadian smoke plumes: $\mathrm{C}_{1}-\mathrm{C}_{10}$ volatile organic compounds (VOCs), $\mathrm{CO}_{2}, \mathrm{CO}, \mathrm{NO}_{2}$, $\mathrm{NO}, \mathrm{HCN}$ and $\mathrm{CH}_{3} \mathrm{CN}$, Atmos. Chem. Phys., 11, 6445-6463, doi:10.5194/acp-11-6445-2011, 2011.

Singh, H. B., O'Hara, D., Herlth, D., Sachse, W., Blake, D. R., Bradshaw, J. D., Kanakidou, M., and Crutzen, P. J.: Acetone in the atmosphere - distribution, sources, and sinks, J. Geophys. Res., 99, 1805-1819, doi:10.1029/93JD00764, 1994.

Sinha, P., Hobbs, P. V., Yokelson, R. J., Bertschi, I. T., Blake, D. R., Simpson, I. J., Gao, S., Kirchstetter, T. W., and Novakov, T.: Emissions of trace gases and particles from savanna fires in southern Africa, J. Geophys. Res., 108, 8487, doi:10.1029/2002JD002325, 2003.

Sinha, P., Hobbs, P. V., Yokelson, R. J., Blake, D. R., Gao, S., and Kirchstetter, T. W.: Emissions from miombo woodland and dambo grassland savanna fires, J. Geophys. Res., 109, D11305, doi:10.1029/2004JD004521, 2004.

Susott, R. A., Olbu, G. J, Baker, S. P., Ward, D. E., Kauffman, J. B., and Shea, R.: Carbon, hydrogen, nitrogen, and thermogravimetric analysis of tropical ecosystem biomass, in Biomass Burning and Global Change, edited by: Levine, J. S., 350-360, MIT Press, Cambridge, MA, 1996.

Tilmes, S., Emmons, L. K., Law, K. S., Ancellet, G., Schlager, H., Paris, J.-D., Fuelberg, H. E., Streets, D. G., Wiedinmyer,
C., Diskin, G. S., Kondo, Y., Holloway, J., Schwarz, J. P., Spackman, J. R., Campos, T., Nédélec, P., and Panchenko, M. V.: Source contributions to Northern Hemisphere CO and black carbon during spring and summer 2008 from POLARCAT and START08/preHIPPO observations and MOZART-4, Atmos. Chem. Phys. Discuss., 11, 5935-5983, doi:10.5194/acpd-115935-2011, 2011.

Val Martin, M., Logan, J. A., Kahn, R. A., Leung, F.-Y., Nelson, D. L., and Diner, D. J.: Smoke injection heights from fires in North America: analysis of 5 years of satellite observations, Atmos. Chem. Phys., 10, 1491-1510, doi:10.5194/acp-10-14912010, 2010.

Vay, S. A., Woo, J.-H., Anderson, B. E., Thornhill, K. L., Blake, D. R., Westberg, D. J., Kiley, C. M., Avery, M. A., Sachse, G. W., Streets, D. G., Tsutsumi, Y., and Nolf, S. R.: Influence of regional-scale anthropogenic emissions on $\mathrm{CO}_{2}$ distributions over the western North Pacific, J. Geophys. Res., 108, 8801, doi:10.1029/2002JD003094, 2003.

Vivchar, A. V., Moiseenko, K. B., and Pankratova, N. V.: Estimates of carbon monoxide emissions from wildfires in northern Eurasia for airquality assessment and climate modeling, Izv. Atmos. Oceanic Phy.+, 46, 281-293, doi:10.1134/S0001433810030023, 2010.

Ward, D. E. and Radke, L. F.: Emission measurements from vegetation fires: A comparative evaluation of methods and results, in: Fire in the Environment: The Ecological Atmospheric, and Climatic Importance of Vegetation Fires, edited by: Crutzen, P. J. and Goldammer, J. G., John Wiley \& Sons, New York, 53-76, 1993.

Warneke, C., de Gouw, J. A., Stohl, A., Cooper, O. R., Goldan, P. D., Kuster, W. C., Holloway, J. S., Williams, E. J., Lerner, B. M., McKeen, S. A., Trainer, M., Fehsenfeld, F. C., Atlas, E. L., Donnelly, S. G., Stroud, V., Lueb, A., and Kato, S.: Biomass burning and anthropogenic sources of CO over New England in the summer 2004, J. Geophys. Res., 111, D23S15, doi:10.1029/2005JD006878, 2006.

Warneke, C., Bahreini, R., Brioude, J., Brock, C. A., de Gouw, J. A., Fahey, D. W., Froyd, K. D., Holloway, J. S., Middlebrook, A., Miller, L., Montzka, S., Murphy, D. M., Peishl, J., Ryerson, T. B., Schwarz, J. P., Spackman, J. R., and Veres, P.: Biomass burning in Siberia and Kazakhstan as an important source for haze over the Alaskan Arctic in April 2008, Geophys. Res. Lett., 36, L02813, doi:10.1029/2008GL036194, 2009.

Warneke, C., Roberts, J. M., Veres, P., Gilman, J., Kuster, W. C., Burling, I., Yokelson, R., and de Gouw, J. A.: VOC identification and inter-comparison from laboratory biomass burning using PTR-MS and PIT-MS, Int. J. Mass. Spectrom., 303, 6-14, doi:10.1016/j.ijms.2010.12.002, 2011.

Weibring, P., Richter, D., Fried, A., Walega, J. G., and Dryoff, C.: Ultra-high-precision mid-IR spectrometer II: system description and spectroscopic performance, Appl. Phys. B-Lasers O., 85, 207-218, doi:10.1007/s00340-006-2300-4, 2006.

Weibring, P., Richter, D., Walega, J. G., and Fried, A.: First demonstration of a high performance difference frequency spectrometer on airborne platforms, Opt. Express, 15, 13476-13495, doi:10.1364/OE.15.013476, 2007.

Wiedinmyer, C., Akagi, S. K., Yokelson, R. J., Emmons, L. K., AlSaadi, J. A., Orlando, J. J., and Soja, A. J.: The Fire INventory from NCAR (FINN): a high resolution global model to estimate 
the emissions from open burning, Geosci. Model Dev., 4, 625641, doi:10.5194/gmd-4-625-2011, 2011.

Yokelson, R. J., Griffith, D. W. T., and Ward, D. E.: Openpath Fourier transform infrared studies of large-scale laboratory biomass fires, J. Geophys. Res., 101, 21067-21080, doi:10.1029/96JD01800, 1996.

Yokelson, R. J., Susott, R., Ward, D. E., Reardon, J., and Griffith, D. W. T.: Emissions from smoldering combustion of biomass measured by open-path Fourier transform infrared spectroscopy, J. Geophys. Res., 102, 18865-18877, doi:10.1029/97JD00852, 1997.

Yokelson, R. J., Goode, J. G., Ward, D. E., Susott, R. A., Babbitt, R. E., Wade, D. D., Bertschi, I., Griffith, D. W. T., and Hao, W. M.: Emissions of formaldehyde, acetic acid, methanol, and other trace gases from biomass fires in North Caroline measured by airborne Fourier transform infrared spectroscopy, J. Geophys. Res., 104, 30109-30125, doi:10.1029/1999JD900817, 1999.

Yokelson, R. J., Bertschi, I. T., Christian, T. J., Hobbs, P. V., Ward, D. E., and Hao, W. M.: Trace gas measurements in nascent, aged, and cloud-processed smoke from African savanna fires by airborne Fourier transform infrared spectroscopy, J. Geophys. Res., 108, 8478, doi:10.1029/2002JD002322, 2003.

Yokelson, R. J., Karl, T., Artaxo, P., Blake, D. R., Christian, T. J., Griffith, D. W. T., Guenther, A., and Hao, W. M.: The Tropical Forest and Fire Emissions Experiment: overview and airborne fire emission factor measurements, Atmos. Chem. Phys., 7, 5175-5196, doi:10.5194/acp-7-5175-2007, 2007a.
Yokelson, R. J., Urbanski, S. P., Atlas, E. L., Toohey, D. W., Alvarado, E. C., Crounse, J. D., Wennberg, P. O., Fisher, M. E., Wold, C. E., Campos, T. L., Adachi, K., Buseck, P. R., and Hao, W. M.: Emissions from forest fires near Mexico City, Atmos. Chem. Phys., 7, 5569-5584, doi:10.5194/acp-7-5569-2007, 2007b.

Yokelson, R. J., Christian, T. J., Karl, T. G., and Guenther, A.: The tropical forest and fire emissions experiment: laboratory fire measurements and synthesis of campaign data, Atmos. Chem. Phys., 8, 3509-3527, doi:10.5194/acp-8-3509-2008, 2008.

Yokelson, R. J., Crounse, J. D., DeCarlo, P. F., Karl, T., Urbanski, S., Atlas, E., Campos, T., Shinozuka, Y., Kapustin, V., Clarke, A. D., Weinheimer, A., Knapp, D. J., Montzka, D. D., Holloway, J., Weibring, P., Flocke, F., Zheng, W., Toohey, D., Wennberg, P. O., Wiedinmyer, C., Mauldin, L., Fried, A., Richter, D., Walega, J., Jimenez, J. L., Adachi, K., Buseck, P. R., Hall, S. R., and Shetter, R.: Emissions from biomass burning in the Yucatan, Atmos. Chem. Phys., 9, 5785-5812, doi:10.5194/acp-9-5785-2009, 2009.

Yuan, B., Liu, Y., Shao, M., Lu, S., and Streets, D. G.: Biomass burning contributions to ambient VOCs species at a receptor site in the Pearl River Delta (PRD), China, Environ. Sci. Technol., 44, 4577-4582, doi:10.1021/es1003389, 2010. 